\title{
NGNP Site 2 Hazards Assessment
}

October 2011

The INL is a

U.S. Department of Energy

National Laboratory

operated by

Battelle Energy Alliance

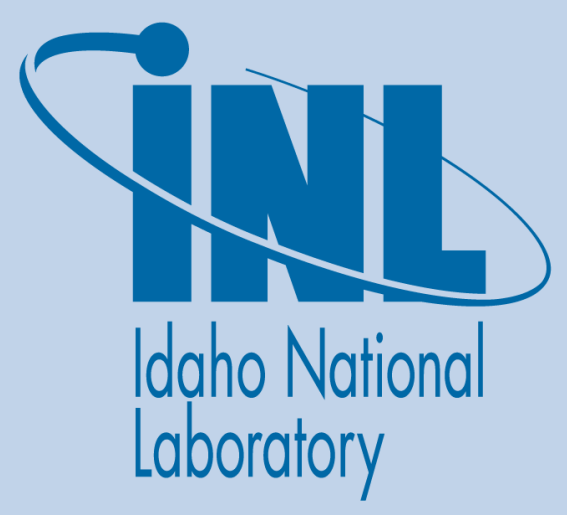

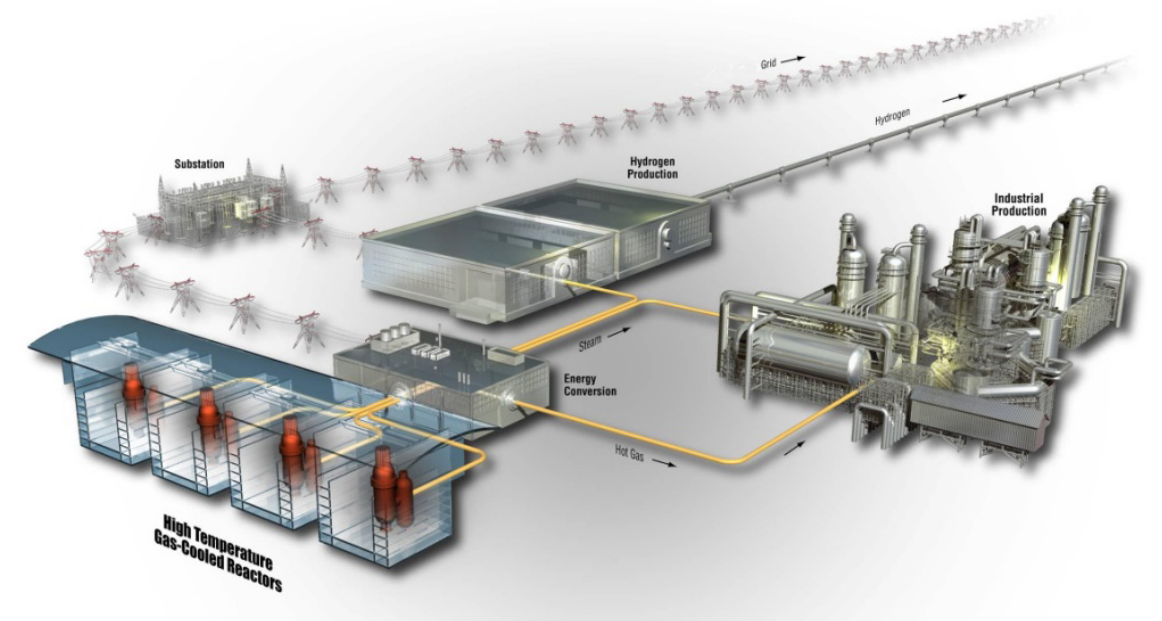




\section{DISCLAIMER}

This information was prepared as an account of work sponsored by an agency of the U.S. Government. Neither the U.S. Government nor any agency thereof, nor any of their employees, makes any warranty, expressed or implied, or assumes any legal liability or responsibility for the accuracy, completeness, or usefulness, of any information, apparatus, product, or process disclosed, or represents that its use would not infringe privately owned rights. References herein to any specific commercial product, process, or service by trade name, trade mark, manufacturer, or otherwise, does not necessarily constitute or imply its endorsement, recommendation, or favoring by the U.S. Government or any agency thereof. The views and opinions of authors expressed herein do not necessarily state or reflect those of the U.S. Government or any agency thereof. 


\section{NGNP Site 2 Hazards Assessment}

October 2011

\section{Idaho National Laboratory \\ Next Generation Nuclear Plant Project \\ Idaho Falls, Idaho 83415}

http://www.inl.gov

Prepared for the

U.S. Department of Energy

Office of Nuclear Energy

Under DOE Idaho Operations Office

Contract DE-AC07-05ID14517 

Next Generation Nuclear Plant Project

NGNP Site 2 Hazards Assessment

INL/EXT-11-23178

Revision 0

October 2011

Approved by:
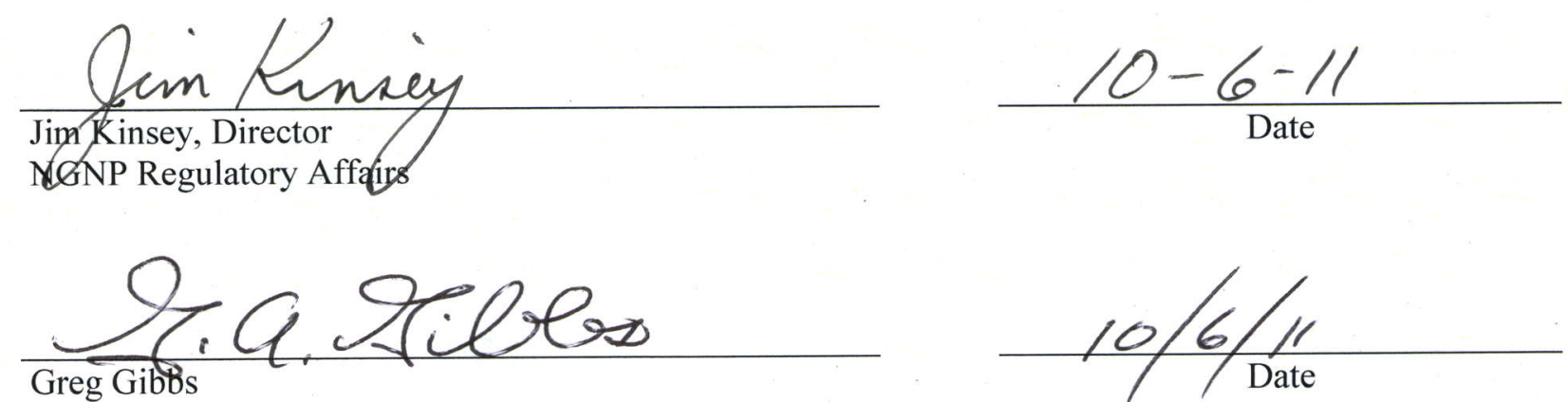

NGNP Project Manager

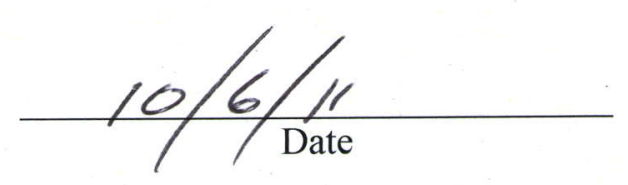





\section{SUMMARY}

The Next Generation Nuclear Plant (NGNP) Project, initiated at Idaho National Laboratory by the U.S. Department of Energy and pursuant to the Energy Policy Act of 2005, is based on research and development activities supported by the Generation IV Nuclear Energy Systems Initiative. The principal objective of the NGNP Project is to support commercialization of high temperature gas-cooled reactor (HTGR) technology. The HTGR is a helium-cooled and graphite-moderated reactor that can operate at temperatures much higher than those of conventional light water reactor (LWR) technologies.

Accordingly, it can be applied in many industrial applications as a substitute for burning fossil fuels such as natural gas and to generate process heat in addition to producing electricity, which is the principal application of current LWRs.

Nuclear energy in the form of LWRs has been principally used in the United States and internationally to generate electricity. However, because the HTGR operates at higher temperatures than LWRs, it can be used to displace the use of fossil fuels in many industrial applications while providing a carbon emission-free energy supply. For example, the energy needs for the recovery and refining of petroleum, for the petrochemical industry, and for production of transportation fuels and feedstock using coal conversion processes, require process heat at temperatures approaching $800^{\circ} \mathrm{C}$. This temperature range is readily achieved by HTGR technology.

This report summarizes a site assessment performed as a part of the NGNP Project to determine hazards and potential challenges that site owners and HTGR designers need to be aware of when developing the HTGR design for co-location at industrial facilities. It preliminarily evaluates the site for suitability, considering certain site characteristics. The objectives of NGNP site hazard assessments are to do an initial screening of representative sites in order to identify potential challenges and restraints to be addressed in design and licensing processes; assure the HTGR technology can be deployed at a variety of sites for a range of applications; evaluate potential sites for potential hazards and describe some of the actions necessary to mitigate impacts of hazards; and provide key insights that can inform the plant design process. This report presents the process methodology and results of an assessment of hazards typical of a class of candidate sites for the potential deployment of HTGR reactor technology. The assessment considered health, safety, and other important siting characteristics to determine the potential impact of identified hazards and potential challenges presented by the location for HTGR technology. ${ }^{\text {a }}$

This assessment was conducted based on the methodology for evaluating key characteristics of a site as presented in NGNP-LIC-ETR-RPT-0001, "Procedure for Site Hazards Evaluation and Impact Assessment." Because HTGR designs are still evolving in the early design phases, a great deal of specific information (key site parameters that bear on the design and site characteristics assumed in the design) was not available to support this assessment. However, some plant parameter envelope information from General Atomics for the Gas-Turbine, Modular Helium Reactor design was used in limited applications to support this assessment (e.g., bounding water use requirements, accident source term, and foundation embedment depth).

This is the second site to be assessed as a part of the NGNP Project, hereinafter referred to as Site 2 or the Waterford site. Site 2 is located within an industrial center near the Mississippi River about $25 \mathrm{mi}$ northwest of New Orleans, LA. The site is adjacent to an existing nuclear power plant (Waterford 3).

a It is noted that the generation, transmission, distribution, and sale of electricity implicates a number of federal and state laws, rules, and regulations. An evaluation of these laws and regulatory requirements is beyond the scope of this assessment. 
Based on the results of the assessment presented and discussed in this report, there are a number of technical and environmental areas that require further evaluation. It was determined that the hazards at Site 2, or similar sites, could be reasonably addressed and mitigated to support the licensing and deployment of a co-located HTGR plant. The more significant areas identified in this evaluation, in terms of necessary design (technology or site geotechnical) and construction mitigation actions, are:

- The proximity of a nearby railroad line to the site. This factor presents potential issues with respect to impacts from hazardous materials and security. Physical security considerations may create some specific needs for the design and will require further evaluation, depending on the final location selected for siting the reactors and the technology selected. Adequate standoff distance may be a challenge for Site 2, depending on the final area chosen.

- A natural gas pipeline is located near the existing Waterford 3 nuclear plant. If this pipeline were to rupture a detonable plume might result. Since the HTGR site is closer to this gas line than is the Waterford 3 nuclear complex, the effects of an explosion would likely generate higher peak overpressures.

- The site exhibits shallow groundwater conditions in soils that are prone to settlement when dewatered. This can create risk of localized surface subsidence during any dewatering operations that would accompany construction of an HTGR facility.

- Equilibrated groundwater hydrodynamic pressures on the basemat (approximately $160 \mathrm{ft}$ deep) of the post-constructed HTGR facility must be considered in the HTGR facility design.

- Current and future planned flood protection and mitigation features in the vicinity of the site, such as levee systems, reservoirs, and diversion structures maintained by the US Army Corps of Engineers, would need to be revalidated as applicable to adequately protect HTGR modules from flooding at this site.

- Because of the site's deep soil conditions and the anticipated planned depth of excavation (possibly $160 \mathrm{ft}$ ), the project will need to address additional challenges associated with dewatering, excavation of retaining walls, and foundation design intended to mitigate excess settlement.

It is noted that the above summary listing does not include various other challenges and potential hazards on or around Waterford site. This includes bulk storage of hazardous substances at neighboring industrial facilities. Although these are important considerations for HTGR design and siting, they were not considered to be significant HTGR challenges since they have been previously addressed successfully at Waterford 3. It is likely that these issues can be similarly addressed for the HTGR facility.

While the evaluations contained in this report provide designers with preliminary insights they may be addressed in HTGR design, should this or any site similar to this location be identified for siting a new nuclear plant, additional in-depth evaluations will be needed once a design is selected. These evaluations would include detailed site investigations in hydrological, geotechnical, and meteorological areas. Detailed evaluations will be needed to ensure physical security can be achieved and additional environmental and sociological investigations and permitting action will be required.

In addition to the insights provided in this report for the HTGR designers, an overview assessment was performed to identify impacts that the construction and operation of the HTGR facility may have on the existing Waterford 3 Nuclear Plant. The results of that assessment, presented in Appendix B, include the following:

- Effects of postulated HTGR radiological releases on the existing Waterford 3 safety systems, Technical Specification requirements, and associated dose analyses

- The need to integrate the security and emergency planning functions for Waterford 3 and the HTGR facility 
- The consideration of hazards or potential impacts on Waterford 3 during the HTGR facility's construction phase (site access/egress, excavation, wind-generated construction-related missiles, etc.). 


\section{CONTENTS}

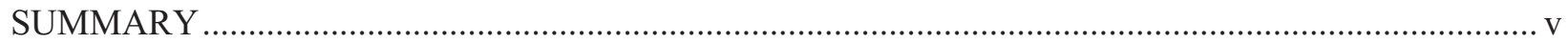

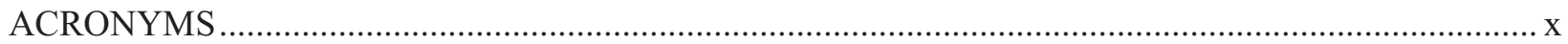

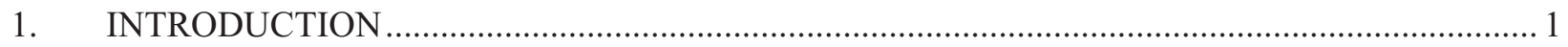

2. SUMMARY DESCRIPTION OF ASSESSMENT PROCESS ................................................ 4

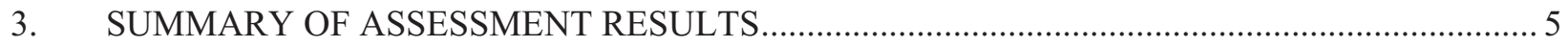

3.1 Geology, Seismology, and Geotechnical Engineering ........................................................ 5

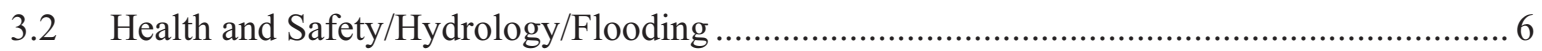

3.3 Health and Safety/Hydrology/Water Availability ............................................................. 6

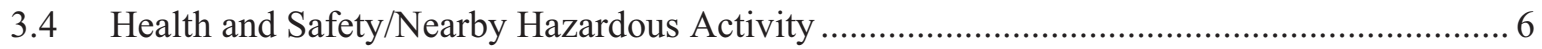

3.5 Other Site Characteristics/Security Features.................................................................... 7

3.6 Other Site Characteristics/Land Availability .................................................................. 7

3.7 Other Site Characteristics/Site Constructability Factors ................................................... 7

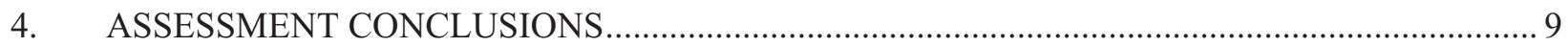

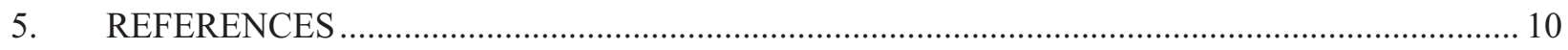

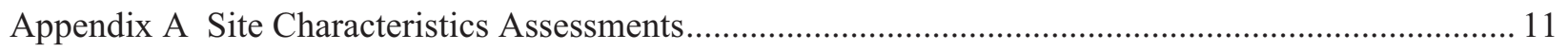

A-1. Health and Safety/Geology, Seismology and Geotechnical Engineering/Site Geotechnical.

A-2. Health and Safety/Geology, Seismology, and Geotechnical Engineering/Seismic

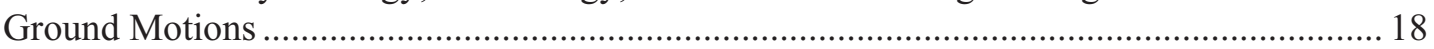

A-3. Health and Safety/Geology, Seismology and Geotechnical Engineering/Global

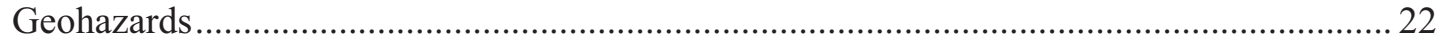

A-4. Health and Safety/Hydrology/Flooding ....................................................................... 27

A-5. Health and Safety/Hydrology/Water Availability ............................................................... 34

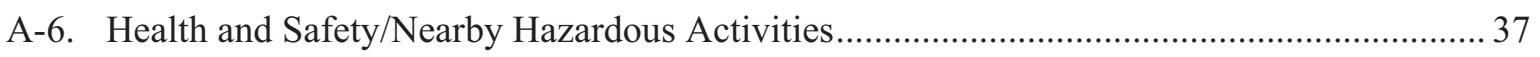

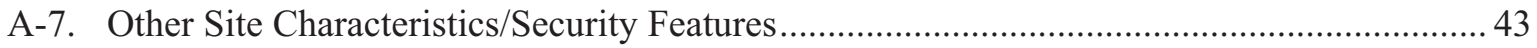

A-8. Other Site Characteristics/Land Availability .................................................................... 52

A-9. Other Site Characteristics/Site Constructability Factors ................................................... 55

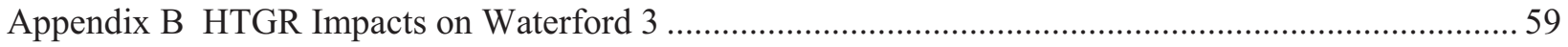

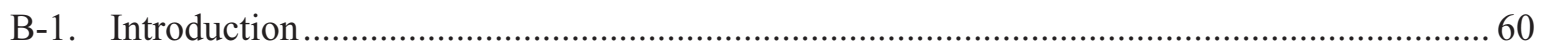

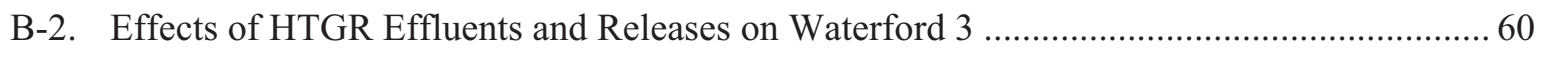

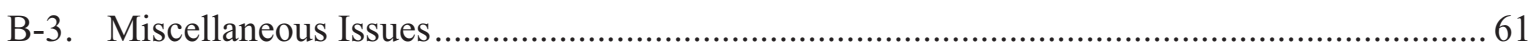




\section{ACRONYMS}

$\begin{array}{ll}\text { ANS } & \text { American Nuclear Society } \\ \text { ANSI } & \text { American Nuclear Standards Institute } \\ \text { CFR } & \text { Code of Federal Regulations } \\ \text { CSDRS } & \text { certified seismic design response spectrum } \\ \text { EAB } & \text { exclusion area boundary } \\ \text { EPA } & \text { Environmental Protection Agency } \\ \text { FSAR } & \text { final safety analysis report } \\ \text { GIS } & \text { geographic information system } \\ \text { GT-MHR } & \text { Gas-Turbine, Modular Helium Reactor } \\ \text { HTGR } & \text { high temperature gas-cooled reactor } \\ \text { LLEA } & \text { local law enforcement agencies } \\ \text { LPG } & \text { liquefied petroleum gas } \\ \text { LWR } & \text { light water reactor } \\ \text { msl } & \text { mean sea level } \\ \text { NGNP } & \text { Next Generation Nuclear Plant } \\ \text { NPIS } & \text { Nuclear Plant Island Structure } \\ \text { NRC } & \text { Nuclear Regulatory Commission } \\ \text { NUREG } & \text { Nuclear Regulatory Report } \\ \text { OBE } & \text { operating basis earthquake } \\ \text { OCA } & \text { owner controlled area } \\ \text { PA } & \text { protected area } \\ \text { PAG } & \text { protective action guidelines } \\ \text { PDF } & \text { plant design flood } \\ \text { PGA } & \text { peak ground acceleration } \\ \text { PGD } & \text { peak ground displacement } \\ \text { PGV } & \text { peak ground velocity } \\ \text { PMF } & \text { probable maximum flood } \\ \text { PMH } & \text { probable maximum hurricane } \\ \text { probable maximum precipitation } \\ \text { regulatory guide }\end{array}$


SSE safe shutdown earthquake

TNT trinitrotoluene

TS technical specification

UHS ultimate heat sink

$\mathrm{Vp} \quad$ compression wave velocity

Vs shear wave velocity 


\section{NGNP Site 2 Hazards Assessment}

\section{INTRODUCTION}

The Next Generation Nuclear Plant (NGNP) Project, initiated at Idaho National Laboratory by the U.S. Department of Energy pursuant to the Energy Policy Act of 2005, is based on research and development activities supported by the Department of Energy Generation IV Nuclear Energy Systems Initiative. The principal objective of the NGNP Project is to support commercialization of high temperature gas-cooled reactor (HTGR) technology. The HTGR is a helium-cooled and graphitemoderated reactor that can operate at temperatures much higher than those of conventional light water reactor (LWR) technologies. Accordingly, it can be applied in many industrial applications as a substitute for burning fossil fuels such as natural gas, to generate process heat in addition to producing electricity, which is the principal application of current LWRs.

Nuclear energy in the form of LWRs has been principally used in the United States and internationally for the generation of electricity. However, because the HTGR operates at higher temperatures than LWRs, it can be used to displace the use of fossil fuels for generation of process heat in many industrial applications, providing a carbon emission-free energy supply. For example, the energy needs for recovery and refining of petroleum, for the petrochemical industry, and for production of transportation fuels and feedstock using coal conversion processes, require process heat at temperatures approaching $800^{\circ} \mathrm{C}$. This temperature range is readily achieved by the HTGR technology.

This report summarizes a site assessment performed as a part of the NGNP Project to determine hazards and potential challenges that site owners and HTGR designers must consider when developing the HTGR design for co-location at existing industrial/nuclear facilities. The objectives of NGNP site hazard assessments are to identify and initially screen potential challenges and constraints that exist at representative industrial sites to be addressed in design and licensing processes; provide assurance that the HTGR technology can be deployed at a variety of sites for a range of applications; describe some of the actions necessary to mitigate impacts of hazards; and provide key insights that can inform the plant design process. This report summarizes potential impacts from significant hazards typical of a class of candidate sites for potential deployment of HTGR reactor technology. The assessment considered certain health, safety and other important siting characteristics to determine the potential impact of identified hazards and potential challenges presented by the location for this technology. ${ }^{\mathrm{b}}$

The site assessed is this report, hereinafter referred to as Site 2, is located within an industrial center near the Mississippi River about 25 mi northwest of New Orleans, LA as shown in Figure 1. Site 2 is fairly flat. Contour data indicates the overall site elevation is approximately $10 \mathrm{ft}$. above mean sea level (msl). There is a network of levees around waterways surrounding Site 2 that are used to protect existing industrial facilities. Levee heights varying from $15 \mathrm{ft}$ to $22 \mathrm{ft}$ above $\mathrm{msl}$ are designed to provide protection against maximum probable flood events.

The area that was evaluated in this assessment is described in the Waterford 3 Final Safety Analysis Report (FSAR) ${ }^{1}$ and Figure 1.

b It is noted that the generation, transmission, distribution, and sale of electricity implicates a number of federal and state laws, rules, and regulations. An evaluation of these laws and regulatory requirements is beyond the scope of this assessment. 


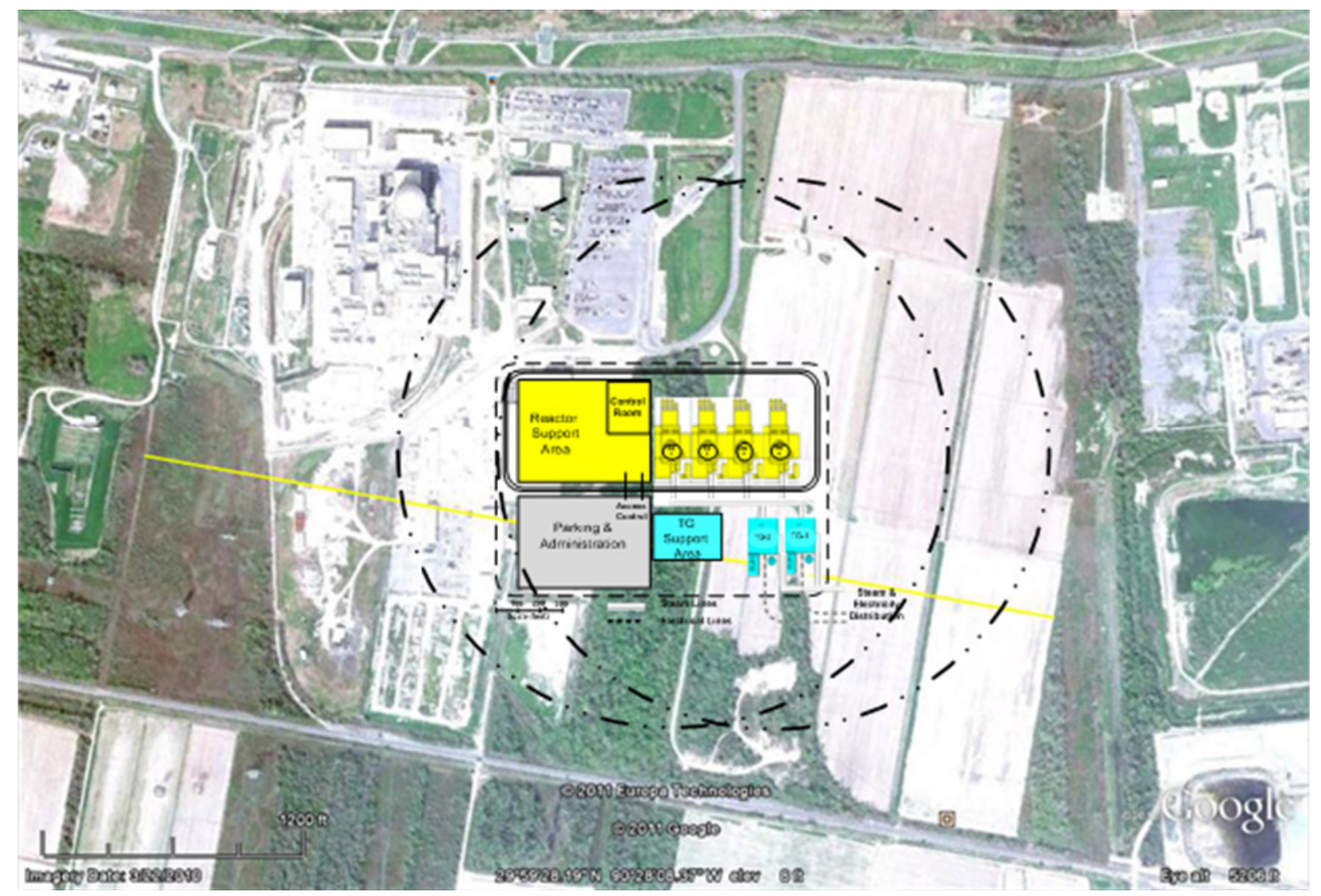

Figure 1. Hazards assessment location-Waterford Site (Site 2).

The assessment was conducted based on the methodology for evaluating key site characteristics as presented in NGNP-LIC-ETR-RPT-0001, "Procedure for Site Hazards Evaluation and Impact Assessment." ${ }^{2}$ Because the HTGR designs are still in the early developmental phases, specific information (key site parameters that bear on the design and site characteristics assumed in the design) was not available for use in this assessment. However, some plant parameter envelope information from General Atomics for the Gas-Turbine, Modular Helium Reactor (GT-MHR) design ${ }^{3}$ was used to support a limited notional application for this assessment (e.g., bounding water use requirements, foundation embedment depth). Information from the GT-MHR was used as design input because it provided the necessary data, was readily available, and had already been prepared for nuclear plant siting evaluations. In this assessment existing sources of documented information were utilized. No field investigations were conducted.

It was assumed that the HTGR facility would consist of a four reactor module nuclear plant $(2,000$ to 2,400 MW thermal) that co-generates steam, electricity for general use in the plant, and hot gas for use in a nearby chemical processing facility, to provide the requisite performance and reliability. The approximate land area requirement for this four-module nuclear plant (including all facilities and support buildings) is estimated at about $1,100 \times 1,500 \mathrm{ft}$. (It is noted that additional land area would be required if the plant design includes a closed cooling configuration with cooling towers.)

Section 2 of this report summarizes the assessment process and methodology. Section 3 summarizes the results of the assessment. Conclusions with regard to the primary objectives are provided in Section 4. General references cited in the report body are listed in Section 5. 
Detailed results of the evaluations, which can be used for more detailed technical evaluations and plant design input, are provided in Appendix A. Each evaluation includes a brief description of the evaluation process specific to the characteristic and key considerations, the evaluation criteria for each characteristic considered, a discussion of the assessment performed, a discussion of risks and potential risk mitigation measures, and the references used in support of the evaluation.

Appendix B provides a summary description of potential hazards and key impacts that HTGR facility design, licensing, construction, and operation may have on the existing adjacent Waterford 3 nuclear plant. 


\section{SUMMARY DESCRIPTION OF ASSESSMENT PROCESS}

Selected key site characteristics in the areas of health and safety, and other siting characteristics (e.g., land availability, security), were evaluated as described in the "Procedure for Site Hazards Evaluation and Impact Assessment." The procedure contains an 18 template system with 24 separate areas (site characteristics) of evaluation. An earlier site hazards assessment was performed using all of the procedure templates. Using the experience gained from the first site assessment, only a portion of these templates were considered necessary during the evaluation of Site 2. Guidance for each procedure template was developed using U.S. Nuclear Regulatory Commission (NRC) regulatory guidance documents and industry documents such as those identified in Refs. 4 through 9. It is important to note that the template evaluation system does not rank a site or area but rather provides the framework of information needed to assess potential hazards and potential challenges of each individual site or area. The templates used in this report address the following site characteristics:

Health and safety characteristics:

- Geology, Seismology, Geotechnical Engineering

- Site Geotechnical

- Seismic Ground Motions

- Global Geohazards

- Hydrology

- Flooding

- Water Availability

- Nearby Hazardous Activities.

Other site characteristics include:

- Security Features

- Land Availability

- Site Constructability Factors.

A kickoff meeting was held with the Site 2 owner in August 2011 who provided an overview of the site. Much of the information related to assessment of Site 2 is publically available in the FSAR for the nearby Waterford 3 nuclear power station. No significant independent research for this evaluation was conducted beyond reviewing the Waterford 3 FSAR-related documentation.

Because the HTGR design project is in the early design phase, bounding estimates for some of the technology-specific design parameters were used. Assumptions were made if specific data were not available. As mentioned above, some representative GT-MHR design information from an HTGR vendor (General Atomics) was used in a limited application for this assessment (e.g., bounding water use requirements, accident source term, and foundation embedment depth).

The evaluation templates set forth information such as a description of the characteristic being evaluated, discussions on the importance of the site characteristic, and the criteria that must be satisfied in order for the site to be assessed as acceptable, requiring further evaluation, or otherwise not suitable. The key characteristics selected for this examination were evaluated using the respective template as a guide and coupled with professional judgments made on that evaluation. The goal was to ascertain the suitability of the site with respect to that characteristic and the potential hazards and challenges that Site 2 may present to a design. For this assessment, templates were applied to existing available information without new analyses or additional field work. Each area was then classified as either "Acceptable Site," "Site Requires Further Evaluation," or "Site Not Suitable," depending on the specific guidance provided in the template and the technical judgment of the evaluator. 


\section{SUMMARY OF ASSESSMENT RESULTS}

As discussed above, selected characteristics were evaluated using guidance established in Ref. 2. Sitespecific information contained in the Waterford 3 FSAR was used to evaluate these characteristics and a judgment made based on that evaluation as to the suitability of Site 2 with respect to that characteristic. Hazards and potential challenges to be considered and addressed in the HTGR design were identified. In some cases, the evaluations concluded that Site 2 could not be classified acceptable because available information was not specific enough or sufficient information was lacking. For example, a railroad line passes very close to the proposed site, and its potential impact on an HTGR plant could not be precisely determined in the course of this screening-level assessment. Thus, several related Site 2 evaluations involving hazardous material impacts and security issues were noted as requiring further evaluation.

A summary of the evaluation of each site characteristic is discussed below. Detailed evaluations of each characteristic can be found in the applicable sections of Appendix A.

\subsection{Geology, Seismology, and Geotechnical Engineering}

The Waterford 3 FSAR outlines a seismic analysis that was performed on a land parcel immediately adjacent to the site being evaluated. The evaluation was performed in accordance with NRC guidance and requirements applicable to a nuclear power plant. This analysis demonstrates the location to be of generally acceptable seismic character with respect to the Waterford 3 LWR design. This is a site that offers a relatively low potential for seismic ground motion. Presuming that the final HTGR design will establish seismic design criteria that comply with the regulatory requirements summarized in Section A-1, the site was considered "Acceptable Site" for purposes of this evaluation.

The Waterford 3 FSAR also examined the potential for global geohazards in an area inclusive of the site being evaluated. The analysis noted the locale as being a deep-soils site with no unrelieved residual stresses in subsurface sediments. No cavernous or karst terrain is present. There is no potential for natural slope failure or volcanism. Growth faults do exist in the region and can be associated with numerous salt domes that do occur in the area. The prospect of subsidence from regional mineral extraction activities (oil, gas, salt, sulfur) is low at Site 2. Regional subsidence attributable to groundwater extraction is not believed sufficient to affect site structures. Based on this information, this site was deemed "Acceptable Site" for purposes of screening the global geohazards that might impact an HTGR facility.

A site geotechnical (subsurface stability and foundation affects) assessment involves evaluation of site-specific subsurface conditions and issues that could affect plant safety, plant function, or present unusual difficulty or costs for construction of a plant. The loading history and foundation properties of soils underlying the site are described in the Waterford 3 FSAR. In general, the unconsolidated sedimentary materials underlying the prospective site are acceptable to support construction of an industrial facility.

However, the location does exhibit shallow groundwater conditions in soils that are prone to settlement when dewatered. For instance, the adjacent Waterford 3 nuclear plant experienced nine inches of settlement during construction (Section 2.4.1.1 of Ref. 1). This can create the risk of localized surface subsidence during the dewatering operations that would accompany construction of an HTGR facility. Similarly, equilibrated groundwater hydrodynamic pressures on the approximately $160 \mathrm{ft}$ deep basemat of the post-constructed HTGR facility must be considered in the HTGR facility design. Because foundational stability and the groundwater regime of the area have a direct bearing on yet-to-be established acceptance criteria for the HTGR design, it is suggested that further attention be directed to the issue. On this basis, the site was deemed "Site Requires Further Evaluation" with respect to geotechnical issues. 


\subsection{Health and Safety/Hydrology/Flooding}

Safety related structures, systems, and components for a new candidate nuclear power plant site must be designed to withstand the worst hydrologic conditions and flooding caused by an appropriate combination of several hypothetical events. These hypothetical events include probable maximum flood, probable maximum hurricane and surge, probable maximum precipitation, tsunami and seiche, ice effects, effects of levee and dam failures, effects of seismic events, wave action, low water considerations, and groundwater considerations. Existing LWR regulations require that nuclear power plants be designed to prevent the loss of capability to perform the required safety functions to achieve and maintain shutdown considering the most severe (design basis) flood or other hydrologic conditions that may occur at a specific site.

The nearby Waterford 3 plant was previously evaluated for hazards associated with potential flooding and hydrological conditions. Risks were found acceptable for that LWR design. To evaluate the ability of the HTGR facility to withstand worst-case flooding scenarios and combinations, the site elevation, plant layout and design, data, analyses, and all flood-related factors must be considered relative to current regulatory requirements as outlined in Section A-4. In addition, current and future planned flood protection and mitigation features in the vicinity of the site, such as levee systems, reservoirs, and diversion structures maintained by the US Army Corps of Engineers, would need to be revalidated as applicable to ensure adequate flood protection for new HTGR modules. As a result, with respect to HTGR flooding risk, this is a site that requires further evaluation.

\subsection{Health and Safety/Hydrology/Water Availability}

If the plant is designed to use water from either the Mississippi River or the local water district as the primary water source, an ample source is available and water availability would be acceptable. The evaluation classified Site 2 as an "Acceptable Site" on that basis. However, if water is required from the groundwater aquifers, additional study would be required to determine if an adequate water supply exists during all postulated conditions without impacting other users or causing unacceptable ground subsidence. Exercising this contingency would result in a site evaluation for water availability of "Site Requires Further Evaluation."

\subsection{Health and Safety/Nearby Hazardous Activity}

The Waterford 3 FSAR provides an analysis of hazardous activities within $5 \mathrm{mi}$ of Site 2. For the worst case accidents, peak overpressures are calculated where applicable. These values should be considered in the HTGR structural design. An analysis was also performed of the impact of nearby chlorine hazards on the Waterford 3 control room. Given that the design the Waterford 3 control room has chlorine detectors that automatically isolate the control room, the impact of chlorine hazards are considered acceptable for the HTGR.

Other activities within $5 \mathrm{mi}$ of Site 2 will also require consideration by HTGR designers. The primary sources of these hazards are:

- The transport of hazardous materials (gasoline, liquefied petroleum gas (LPG), hazardous chemicals, etc.) in the vicinity of the site by various means (barge, rail, roadway), nearby natural gas pipelines, LPG lines, and/or flammable stationary sources

- Potential aircraft impacts

- Radiological impacts from the operation of the Waterford 3 nuclear plant. 
Because of considerations relative to various nearby hazardous activities, the location was deemed "Site Requires Further Evaluation."

\subsection{Other Site Characteristics/Security Features}

The review of hazards and associated insights related to the topic of security features resulted in the following observations:

- The site is in close proximity to facilities and structures associated with the Waterford 3 nuclear plant complex. Although these facilities have tall building elevations and are nearby, the buildings are within a protected area and hence do not pose a security threat to Site 2 . Other buildings in the area require further evaluation.

- The elevation of the overall Waterford site location which encompasses Site 2 changes little in all directions (varying no more than approximately $10 \mathrm{ft}$ ), which is acceptable from a security perspective.

- The proposed boundary for Site 2 is approximately 1,500 ft from the nearby Mississippi River. This provides more distance from potential hazards (e.g., barge traffic carrying hazardous materials) than the existing Waterford 3 nuclear plant.

- A makeup water source is assumed to not be critical to the safe shutdown of the HTGR facility. Based on distance away from the river and the expected configuration of the HTGR plant cooling system, Site 2 is determined to be acceptable.

- The closest railroad to the site is the Union Pacific Railroad, which runs across Entergy's property. The rail line is close to the expected protected area boundary for Site 2. Based on the location of this railroad line with respect to the site and the proximity of chemical facilities, Site 2 is considered to offer some risk that will require further evaluation.

\subsection{Other Site Characteristics/Land Availability}

There are several locations on Site 2 with sufficient available area to site a four-module HTGR facility or larger. Each of the potential locations has suitable access for supply of steam and transmission of electricity to the local industrial facilities and to the existing nuclear plant substations for access to the regional electrical grid. This makes Site 2 an "Acceptable Site."

Each of the potential locations for the HTGR facility was selected to ensure that the exclusion area boundary $(\mathrm{EAB})$ of the facility does not encompass the existing Waterford 3 reactor site, adjacent industrial facilities or, to the extent possible, any publicly accessible road, waterway, railway or residence. The adjacent railroad line is one of the more significant impacts on establishing an acceptable location for the HTGR facility.

\subsection{Other Site Characteristics/Site Constructability Factors}

Site 2 is located adjacent to an operating nuclear plant that has substantial existing infrastructure in place such as transmission lines, major roadways, railways, and barge access. There is also local and state government acceptance of nuclear power. It is assumed that a qualified workforce is available in the area sufficient to support HTGR plant construction. The site is also closely located to other major industrial plants (less than $2 \mathrm{mi}$ from Site 2) that are potential off-takers of energy from the HTGR facility. There are several locations on the Site 2 property that have adequate area and subsurface soil conditions for construction of the HTGR facility. However, because of the site's deep soil conditions (Section 2.5.4 of Ref. 1) and anticipated planned depth of excavation (at least $160 \mathrm{ft}$ ), ${ }^{10}$ the project will need to consider the 
impacts of dewatering, excavation of retaining walls, and foundation design intended to mitigate excess settlement. 


\section{ASSESSMENT CONCLUSIONS}

Based on the results of the assessments presented and discussed in this report, a number of technical and environmental issues require further evaluation before proceeding with formal site permitting and HTGR deployment. Overall, however, Site 2 appears to be viable for siting a modular HTGR complex. The more significant areas identified in this evaluation, in terms of necessary design (technology or site geotechnical) and construction mitigation actions, are:

- The proximity of a nearby railroad line to the site. This factor presents potential issues with respect to impacts from hazardous materials and security. Physical security considerations may create some specific needs for the design and will require further evaluation, depending on the final location selected for siting the reactors and the exact technology selected. Adequate standoff distance may be a challenge for Site 2, depending on the final area chosen.

- A natural gas pipeline is located approximately $0.6 \mathrm{mi}(3,168 \mathrm{ft})$ from the Waterford 3 plant. If this pipeline were to rupture and created a detonable plume, such an explosion could create an overpressure of about $1.0 \mathrm{psi}$ and a reflected overpressure of $2.1 \mathrm{psi}$ at the Waterford- 3 site. Since the HTGR might be located closer to this gas line than is Waterford 3, the effects of an explosion would likely generate higher peak overpressures.

- The site exhibits shallow groundwater conditions in soils that are prone to settlement when dewatered. This can create a risk of localized surface subsidence during the dewatering operations that would accompany construction of an HTGR facility.

- Equilibrated groundwater hydrodynamic pressures on the basemat (approximately $160 \mathrm{ft}$ deep) of the post-constructed HTGR facility must be considered in the HTGR facility design.

- Current and future planned flood protection and mitigation features in the vicinity of the site, such as levee systems, reservoirs, and diversion structures maintained by the US Army Corps of Engineers, would need to be revalidated as acceptable for providing adequate flood protection for newly installed HTGR modules at this site.

- Because of the site's deep soil conditions and anticipated planned depth of excavation (at least $160 \mathrm{ft}$ ), the project will need to address the additional challenges associated with dewatering, excavation of retaining walls, and foundation design intended to mitigate excess settlement.

While this evaluation provides designers with preliminary insights they may need to address in the HTGR design, should this or any site similar to this location be identified for siting a new HTGR nuclear plant, additional in-depth evaluations will be needed once a plant design is selected. These evaluations would include detailed site investigations in the areas of hydrology, geology and meteorology. Detailed evaluations will be needed to ensure physical security can be achieved and additional detailed environmental and sociological investigations and permitting actions will be required. 


\section{REFERENCES}

1. “Waterford 3 Final Safety Analysis Report,” Revision 301 (09/07).

2. NGNP-LIC-ETR-RPT-0001, "Procedure for Site Hazards Evaluation and Impact Assessment," Revision 1, September 2009.

3. PC-000507, "GT-MHR Plant Parameter Envelope Supporting Early Site Permitting," Revision 0, General Atomics, April 11, 2003.

4. NUREG-1555, "Standard Review Plans for Environmental Reviews for Nuclear Power Plants."

5. NUREG-0800, "Standard Review Plan for the Review of Safety Analysis Reports for Nuclear Power Plants: LWR Edition."

6. Regulatory Guide (RG) 4.7, "General Site Suitability Criteria for Nuclear Power Stations."

7. Draft Regulatory Guide DG-4015 (Proposed Revision 1 of Regulatory Guide 4.2, Supplement 1, dated September 2000) "Preparation of Environmental Reports for Nuclear Power Plant License Renewal Applications."

8. RG 1.206, "Combined License Applications for Nuclear Power Plants (LWR Edition)."

9. Electric Power Research Institute Siting Guide, "Site Selection and Evaluation Criteria for an ESP Application," No. 1006878, March 2008.

10. INL/EXT-11-23282, "NGNP Project Evaluation of Siting a HTGR Co-generation Plant on an Operating Commercial Nuclear Power Plant," Revision 0, October 2011. 


\section{Appendix A}

\section{Site Characteristics Assessments}




\section{Appendix A \\ Site Characteristics Assessments}

\section{A-1. Health and Safety/Geology, Seismology and Geotechnical Engineering/Site Geotechnical}

\section{A-1.1 Description}

Site geotechnical (subsurface conditions and foundation stability) assessment involves evaluating site-specific geologic and geotechnical conditions or issues that could affect plant safety, plant function, or present unusual difficulty or cost for construction of a plant. Specific issues/conditions that fall under this category, as defined in the U.S. Nuclear Regulatory Commission (NRC) Standard Review Plan (SRP), NUREG-0800, (Ref. SGT-1) include subsidence, karst/dissolution, uplift/heave (stress relief), collapse/settlement, localized altered or weak zones, irregular weathering profiles, weak bedrock structures or shear zones, unstable mineralogy, seismically-induced ground failure (e.g., liquefaction, lateral spreading), soil amplification of seismic ground motions, and high or unusual groundwater conditions. Evaluation of these issues requires characterization of the site-specific geologic and soil stratigraphy and composition, geologic structure and stress history (e.g., past glacial loading, erosional stress relief, tectonic stress), subsurface material engineering properties (e.g., shear strength, density, compressibility, stress-relief, or saturation-induced weakening), groundwater conditions, and impacts of site construction activities (e.g., fill and foundation surcharge loading, excavation-induced stress relief).

Guidelines for the evaluation of site geotechnical conditions to ensure meeting the guidance of the SRP and requirements of 10 CFR Part 50, Appendix A (Ref. SGT-2), and 10 CFR Part 100, Section 100.23 (Ref. SGT-3), are presented in Regulatory Guide (RG) 1.132 "Site Investigations for Foundations of Nuclear Power Plants" (Ref. SGT-4), RG 1.138 "Laboratory Investigations of Soils for Engineering Analysis and Design of Nuclear Power Plants" (Ref. SGT-5), RG 1.198 "Procedures and Criteria for Assessing Seismic Soil Liquefaction at Nuclear Power Plant Sites" (Ref. SGT-6), and RG 4.7 "General Site Suitability Criteria for Nuclear Power Stations" (Ref. SGT-8).

As outlined in these regulatory guides, characterization of site geotechnical conditions and subsurface variability for design-level studies require extensive subsurface investigations and testing. Generally speaking, this level of effort has been achieved for the overall site as a result of previous Waterford 3 nuclear plant licensing actions with the NRC. The potential regional, local, and site-specific geotechnical conditions have been previously assessed and compared against NRC evaluation criteria applicable at the time of plant licensing. This analysis is summarily documented in the Waterford 3 FSAR (Ref. SGT-9).

Notwithstanding the existence of Ref. SGT-9, a geotechnical evaluation of a prospective site is to nominally include a review of existing regional and local maps containing geotechnical related information in a consistent approach as specified in RG 1.208 (Ref. SGT-7) including (as appropriate) maps of the $25 \mathrm{mi}(40 \mathrm{~km}), 5 \mathrm{mi}(8 \mathrm{~km})$, and $0.6 \mathrm{mi}(1 \mathrm{~km})$ radii around the site. These maps are to be used to identify the general geologic setting, geologic formations and stratigraphy, stress history, and possible global geohazards (e.g., large-scale landsliding, young Quaternary geologic deposits potentially susceptible to liquefaction, active tectonic zones, evidence for past glaciation, etc.). Large-scale state or local geologic and geotechnical hazard maps can also provide useful information to evaluate potential major geotechnical hazards or issues. Brief descriptive narratives can be developed for identified geotechnical hazards or issues that summarize the hazard/issue and define its potential impacts.

The evaluation of site geotechnical conditions is performed by review of existing geoscience data to understand the geologic setting and depositional/stress history and site subsurface exploration and 
material testing. Geologic reconnaissance (ground and aerial) may be necessary. However, as mentioned previously, data and analysis from previous geologic, geophysical, groundwater, and geotechnical studies performed at the site and in the area in connection with Waterford 3 comprise an extensive resource concerning the Site 2-specific evaluation of potential geotechnical hazards.

The typical approach with regards to addressing adverse site geotechnical issues is avoidance where possible. However, as opposed to other geologic and seismologic hazards (e.g., vibratory ground motions and permanent ground deformation), many geotechnical issues can be mitigated using industry standard approaches to site preparation, ground improvement, and foundation design. Typical mitigation approaches include: ground improvement through grouting or other techniques (for mitigation of shallow liquefaction or weak soils), deepening of foundations, groundwater pumping or control, and overexcavation (removal of weak or unsuitable surface soils or weathered zones). Therefore, geotechnical issues typically are not considered to be exclusionary criteria but rather are considered as avoidance or preference criteria when comparing alternative sites. Mitigation measures, if proposed, must consider the specific foundation performance criteria for the plant design for the selected nuclear plant and increased investigative and analytical work when compared to less challenged sites.

\section{A-1.2 Importance}

General Design Criterion 2, "Design Bases for Protection Against Natural Phenomena," of Appendix A, "General Design Criteria for Nuclear Power Plants," to 10 CFR Part 50, "Licensing of Production and Utilization Facilities," (Ref. SGT-2) requires that structures, systems, and components (SSCs) important to safety be designed to withstand the effects of natural phenomena such as earthquakes and geologic hazards (including adverse site subsurface or geotechnical conditions) without loss of capability to perform their safety functions. Unstable soil and rock or adverse geologic, geotechnical, or groundwater conditions may pose an unacceptable risk to the ability of safety related SSCs to perform required function(s). 10 CFR Part 100, Section 100.23, "Geologic and Seismic Siting Criteria" (Ref. SGT-3) defines criteria for evaluating the suitability of a proposed site based on consideration of geologic, geotechnical, geophysical, and seismic characteristics. The SRP, Section 2.5.4, "Stability of Subsurface Materials and Foundations," provides the basis for the evaluation of site investigations used to determine soil and rock properties and characteristics needed in the analysis and design of foundations and earthworks for proposed nuclear power plants.

\section{A-1.3 Risk}

Regulatory documents do not define exclusionary criteria for geotechnical issues. Instead, they suggest avoidance coupled with detailed characterization of site geotechnical conditions, subsurface material properties, and their variability. Site characteristics and material properties are then compared against required site parameters and other performance criteria that would be defined for the selected nuclear plant design to verify site suitability with respect to plant performance. This includes foundation stability and tolerable settlements. Site geotechnical conditions are also assessed to verify that construction of the plant can be reasonably performed and to define general mitigation approaches to address any geotechnical issues that cannot be reasonably avoided. A significant licensing risk is accepted for any site that is potentially impacted by major geotechnical hazards or that have multiple geotechnical issues requiring substantial mitigation. 


\section{A-1.4 Evaluation Criteria}

A site is classified as "Acceptable Site" if there are generally favorable site geotechnical conditions and no identified major geotechnical hazards.

A site is classified as "Site Requires Further Evaluation" if potential geotechnical hazards exist that can be reasonably mitigated and/or if some site improvement or special foundation approaches might be required.

A site is classified as "Site Not Suitable" if major or multiple geotechnical hazards exist or if highly adverse site conditions exist.

NUREG-0800 (Ref. SGT-1) describes the expected data sources, level of investigation, and evaluation criteria for screening site geotechnical conditions that are acceptable for safety related SSCs. Sites that are not classified as acceptable will require further evaluation/verification to confirm their suitability and reasonableness of required mitigation measures.

\section{A-1.5 Evaluation}

\section{Acceptable Site}

\section{Site Requires Further Evaluation}

Site Not Suitable

\section{A-1.6 Discussion}

\section{A-1.6.1 Site Type}

The site is located in an industrial center along the lower Mississippi River. It is a relatively flat, marshy area characterized by deep-soils typical of the Mississippi River deltaic plain.

\section{A-1.6.2 Site Geotechnical Analysis}

A geologic description and detailed geologic history of the site and surrounding area can be found in Section 2.5.1.2 of Ref. SGT-9. A brief discussion of the site's seismic potential is provided in the Seismic Ground Motions section of this report, Section A-2. Even though the proposed site is relatively far from capable tectonic faults historically associated with large magnitude earthquakes, the potential does exist for Site 2 to be impacted by a large, distant seismic event due in part to the very deep alluvial and coastal deposits that are present. A seismic event may significantly impact the design of storage tanks, piping systems, retaining walls, transmission lines or other critical structures at the facility that may be sensitive to shaking or differential displacement. Much of this sensitivity is a function of local and regional subsurface material properties and conditions.

The loading history of foundation materials at Site 2 and structural irregularities such as fault occurrences are discussed throughout Section 2.5 of Ref. SGT-9. There are no seismic Category 1 slopes, embankments, or dams in the area the failure of which could adversely affect the safety of a proposed nuclear plant (Sections 2.5.5 and 2.5.6 of Ref. SGT-9). A potential for subsidence across the region does exist that can be mostly attributed to petroleum production, groundwater withdrawal, gas production, and crustal movement (Section 2.5.1.3 of Ref. SGT-9). However, with the potential exception of groundwater withdrawal that might result from major construction activities in the immediate area, the probability of subsidence in the vicinity of the evaluated site because of mineral extraction or crustal movement is low. 
Section 2.5.4.1 of Ref. SGT-9 estimated the sedimentary thickness beneath the site to be in excess of $40,000 \mathrm{ft}$. The strata consist mostly of marine shale, shale alternating with sandstone layers, and Pliocene alternating sands and clays. Recent alluvium deposits exist within the upper 50 to $60 \mathrm{ft}$. There is no cavernous or karst terrain in the area. Sediments underlying the site are not subject to stress build-up with formation of deformational zones or other structural weaknesses. Competent rock will likely not be encountered during construction of a facility at Site 2 .

Extensive subsurface investigations concerning the engineering properties of materials that underlie Site 2 have been conducted in connection with the adjoining Waterford 3 nuclear power facility. In support of the NRC licensing, samples were taken from exploratory borings and used in a comprehensive laboratory test program to determine various physical properties such as density and classification of underlying soils. A description of this testing program, including results, is presented in Sections 2.5.4.2 and 2.5.4.4 of Ref. SGT-9. A program of field geophysical surveys and laboratory testing was also performed to determine the seismic and elastic soil properties. This included shear wave (Vs) and compression wave (Vp) velocities, shear moduli, Young's moduli, and Poisson's ratios. The program included up-hole, cross-hole, and refraction seismic surveys and cyclic triaxial tests in conjunction with literature searches.

From these investigations it can be concluded that the sand strata underlying the site by approximately $50 \mathrm{ft}$ or more will not liquefy during the postulated safe shutdown earthquake (SSE) at Waterford 3 (Section 2.5.4.8 of Ref. SGT-9). Unstable conditions of subsurface materials because of mineralogy, lack of consolidation, or water content were not found. Waterford 3 was constructed by removing the soft recent alluvial material to an elevation of $-48 \mathrm{ft} \mathrm{msl}$ and replacing it with compacted sand backfill.

According to Section 2.5.4.5 of Ref. SGT-9, all seismic Category I systems, equipment and components at the Waterford 3 complex are supported by a common reinforced concrete structure. The foundation is designed as a part of the structure such that the combined foundation and structure act as an integral unit. Subsurface pilings were not used for supporting this structure. Instead, a 1-ft-thick compacted shell filter blanket was placed immediately under the common combined structure mat. This shell blanket serves to evenly distribute uplift buoyant forces on the underside of the mat and provides an acceptable working surface. The combined structure bears at elevation $-47 \mathrm{ft} \mathrm{msl}(7 \mathrm{ft}$ into the stiff Pleistocene stratum that underlies the Recent alluvium). At this level, the foundation loads are completely compensated by hydrostatic uplift forces and impart an average stress to the underlying strata approximately equal to the original in situ effective stresses.

It can be assumed that a co-located HTGR facility at Site 2 will face a similar foundation stability engineering design challenge as was addressed during construction of the Waterford 3 plant.

\section{A-1.6.3 Site Groundwater Control}

Excavation at Site 2 will require groundwater control. Absent any mitigation measures, dewatering for HTGR construction will likely impact surface elevations far from the dewatered site as a result of drawing down the water table. Drawing down the water table increases the effective stresses within the soil column thereby inducing consolidation/compression of the deeper soil layers. This results in settlement at the ground surface. This, in turn, may significantly impact nearby structures and adjacent levees. The magnitude of settlement and the area impacted depends on several factors, including the depth of soil profile, soil characteristics from location to location, depth of lowered groundwater, historic groundwater level fluctuations, and magnitude of structural load(s) as well as other site specific factors.

Section 2.5.4.6 of Ref. SGT-9 presents information on groundwater levels in the immediate vicinity of the Waterford 3 facility. This information appears to be generally representative of Site 2. Groundwater 
conditions suggest the site may be underlain by three relatively shallow local aquifers, two of which have been correlated with regional aquifers. These aquifers and their approximate elevations are:

\begin{tabular}{|ccc|}
\hline Aquifer & Description & Evaluation Range (from msl) \\
\hline 1 & $-77 \mathrm{ft} \mathrm{Sand}$ & $-77 \mathrm{ft}$ to $-92 \mathrm{ft}$ \\
2 & Gramercy Aquifer & $-200 \mathrm{ft}$ to $-312 \mathrm{ft}$ \\
3 & Norco Aquifer & $-312 \mathrm{ft}$ to $-500 \mathrm{ft}$ \\
\hline
\end{tabular}

Groundwater induced hydrostatic loads must be a consideration in the design of any subsurface structure in this region. Presuming that the excavation depth of the nuclear heat supply system for the HTGR plant will be in the range of $160 \mathrm{ft}$ (including basemat), significant attention to groundwater management will be necessary during the design and construction of the facility. There will be a need to manage groundwater influent into the construction area and control areal subsidence risks that may accompany a large dewatering activity. Concern must also be directed to evenly distribute uplift buoyant forces on the underside of the HTGR basemat that will be evident after construction dewatering is completed. Similarly, a basemat monitoring program may be necessary to ensure structural integrity is maintained throughout the life of the HTGR facility.

Section 2.5.4.5 of Ref. SGT-9 describes how the excavation, dewatering, and backfill were executed during construction at the Waterford 3 plant. It is believed that the soil/groundwater regime at Site 2 will closely resemble that described in Ref. SGT-9. Consequently, area settlements and heaves may be caused by site excavation and construction dewatering actions. This can differentially affect excavated slope inclination and cause softer lower Recent alluvium materials to move in a direction of least resistance, i.e., into the excavation. This should be thoroughly evaluated during future phases of site investigation. To offset dewatering induced settlement, water-tight sheet pile systems, secant-pile walls or other watertight retaining systems could be used to reduce the impact of dewatering on larger areas of the site. Prior to installation of these systems, pressure grouting "cut off" walls or another construction technique could be used to reduce the groundwater flow at the perimeter of the excavation.

In-depth settlement analysis will need to be performed in order to consider the settlement potential of adjacent structures, piping, utilities, levees or other settlement sensitive structures during required dewatering activities. Environmental impacts of dewatering, such as contaminant transport from adjacent, potentially contaminated sites and/or nearby wetland drainage, should also be studied during later phases of evaluation. Depending upon final HTGR design, the high groundwater conditions of the area may necessitate a permanent dewatering system to support operation of the facility and ensure groundwater levels remain below those assumed in design.

Inundation of the site at the current elevations is considered a relatively low risk (see further discussion in Appendix Section A-4 of this report). Geotechnically, however, inundation can lead to settlement because of increased effective stresses of the underlying soils. Additionally, flooding creates a higher potential for underground structures to become buoyant and possibly cause significant uplift pressures. Additional fill placement may be a method to mitigate this concern. If the area is raised, inundation potential can be significantly reduced or eliminated.

Using the geotechnical information and analysis contained in Ref. SGT-9, it is concluded that Site 2 should meet existing NRC geotechnical qualification standards for a nuclear facility as they might be applied to a co-located HTGR facility. However, issues of foundational stability in very near-surface soils and the high groundwater regime of the area suggest that significant attention will be needed during design, construction, and operation of an HTGR at this site. Based on this analysis, Site 2 was deemed "Site Requires Further Evaluation." 


\section{A-1.7 Risk Mitigation}

A great deal of Site 2 geotechnical information is already available through investigations and analysis previously conducted in connection with the Waterford 3 plant. The risk associated with Site 2 geotechnical characterizations can be further reduced by: (1) collection and documentation of a robust database of existing information and querying of topical and regional experts; (2) use of conservative assumptions regarding site conditions, uniformity, and material properties; (3) use of geologic aerial and field reconnaissance in the site region and location; and (4) collection of site-specific geologic, geophysical, and geotechnical information.

Certain geotechnical hazards may be mitigated through appropriate design practices once sufficient information has been considered for site specific geohazards. Ref. SGT-9, Section 2.5 can serve as one source of information about site-specific risk mitigation measures that might be employed at the site. Based on Ref. SGT-9 information, a significant potential geotechnical hazard may exist concerning the local groundwater regime. The exact nature of this hazard merits further site-specific study and extensive consideration during facility design. While the geotechnical characteristics and site groundwater/area subsidence risks were managed at Waterford 3 through proper design, the greater embedment depth of a HTGR facility may require different engineering approaches. Prudent exploration, testing, evaluation, and through geotechnical engineering design will be necessary in the early phases of an HTGR plant deployment project for a location like Site 2.

\section{A-1.8 References}

SGT-1: U.S. Nuclear Regulatory Commission, NUREG-0800, Section 2.5.4, "Stability of Subsurface Materials and Foundations" and Section 2.5.5, "Stability of Slopes."

SGT-2: $\quad 10$ CFR Part 50, "Licensing of Production and Utilization Facilities," Appendix A, "General Design Criteria for Nuclear Power Plants."

SGT-3: $\quad 10$ CFR Part 100, "Reactor Site Criteria," Section 100.23, "Geologic and Seismic Siting Criteria."

SGT-4: U.S. Nuclear Regulatory Commission, Regulatory Guide 1.132, "Site Investigations for Foundations of Nuclear Power Plants."

SGT-5: $\quad$ U.S. Nuclear Regulatory Commission, Regulatory Guide 1.138, "Laboratory Investigations of Soils and Rocks for Engineering Analysis and Design of Nuclear Power Plants."

SGT-6: $\quad$ U.S. Nuclear Regulatory Commission, Regulatory Guide 1.198, "Procedures and Criteria for Assessing Seismic Soil Liquefaction at Nuclear Power Plant Sites."

SGT- 7: U.S. Nuclear Regulatory Commission, Regulatory Guide 1.208, "A PerformanceBased Approach to Define the Site-Specific Earthquake Ground Motion."

SGT-8: $\quad$ U.S. Nuclear Regulatory Commission, Regulatory Guide 4.7, "General Site Suitability Criteria for Nuclear Power Stations."

SGT-9: "Waterford 3 Final Safety Analysis Report,” Revision 301 (09/07). 


\section{A-2. Health and Safety/Geology, Seismology, and Geotechnical Engineering/Seismic Ground Motions}

\section{A-2.1 Description}

Seismic ground motion assessment involves evaluation of the level of earthquake-induced vibratory motion derived from analyses of regional and local faults, tectonic stress conditions and structures, historic and instrumental seismicity (past earthquake record), paleoseismic features (prehistoric, geologic evidence of past earthquakes), and site geologic/stratigraphic soil conditions (e.g., shear wave velocity profile). The level of seismic ground motion at a specific site can be estimated for a specific probability (hazard) level that is defined by applicable regulatory criteria (e.g., annual probability of exceedance of $\left.1 \times 10^{-4}\right)$. The site-specific seismic ground shaking is typically summarized by a seismic design response spectrum that plots ground acceleration versus frequency of vibration. This response spectrum is then compared against the Certified Seismic Design Response Spectrum (CSDRS) used for the design of the power plant to ensure that site-specific earthquake ground motions are bounded by the design CSDRS for safety-related SSCs.

\section{A-2.2 Importance}

General Design Criterion 2, "Design Bases for Protection Against Natural Phenomena," of Appendix A, "General Design Criteria for Nuclear Power Plants," to 10 CFR Part 50, "Licensing of Production and Utilization Facilities" (Ref. SGM-1), requires that SSCs important to safety be designed to withstand the effects of natural phenomena (such as earthquakes and geologic hazards) without loss of capability to perform their safety functions. Strong vibratory ground shaking or possible ground failure triggered by seismic shaking may pose an unacceptable risk to the continued operability of safety related SSCs. 10 CFR Part 100, Reactor Site Criteria, Section 100.23, "Geologic and Seismic Siting Criteria" (Ref. SGM-2) defines criteria for evaluating the suitability of a proposed site based on consideration of geologic, geotechnical, geophysical, and seismic characteristics. A safe SSE is defined for evaluation of the possible level of ground shaking based on evaluation of potential earthquake sources, past documented earthquakes, and site characteristics. Safety related SSCs must be able to remain functional during and following the site-specific SSE level of ground shaking.

\section{A-2.3 Risk}

The site-specific SSE or ground motion response spectra, such as seismic source model and site characteristics, are used as inputs to determine the ability of safety related SSCs to withstand the predicted levels of seismic shaking. The predicted site ground motions also support assessment of the likelihood of seismically-induced ground failure.

Regulatory Guide (RG) 1.60, "Design Response Spectra for Seismic Design of Nuclear Power Plants" (Ref. SGM-3) defines a smooth response spectrum that is generally used as the basis for many of the CSDRSs reviewed by the NRC. For example, current standard nuclear plant designs for the Central and Eastern United States generally adopt the RG 1.60 spectrum anchored at a maximum Peak Ground Acceleration (PGA) of $0.3 \mathrm{~g}$, with some possible modifications (especially in the high frequency range of the spectrum) to the base-line spectra by individual vendors. The RG 1.60 spectral shape anchored at $0.3 \mathrm{~g}$ PGA is not strictly an exclusionary criteria. However, areas with ground motions that result in an exceedance of the RG 1.60 spectrum and PGA of $0.3 \mathrm{~g}$ are best initially avoided or down-ranked in an initial screening study. The likelihood of an exceedance of the RG 1.60 spectrum and $0.3 \mathrm{~g}$ PGA increases dramatically for high seismic areas and areas near potentially active geologic/tectonic structures. Deep, soft soil sites may be especially susceptible to seismicity due in part to soil amplification and the resulting higher PGA. Peak Ground Velocity (PGV) and Peak Ground Displacement (PGD) may be the controlling 
seismic parameters for deep soil sites instead of PGA. PGV and PGD should be taken into account for deep soil sites located at moderate distances from very large magnitude seismic events because of the low frequency seismic wave attenuation characteristics associated with large magnitude earthquakes and the lower frequency surface waves dominating the ground motion (Ref. SGM-4). For sites very near large earthquakes, PGA would likely be the controlling factor for rock sites as a result of the high frequency seismic wave attenuation characteristics.

A primary technical risk associated with site seismic evaluation is insufficient knowledge of potential earthquake sources and/or site conditions that could potentially cause under-prediction of actual seismic ground motion levels. If site screening suggests seismic ground motions are acceptable yet later detailed studies demonstrate that they are higher and exceed plant design criteria, a late-stage site rejection or potential plant seismic design reevaluation may be required. Regulatory risks associated with seismic evaluation include extensive Requests for Additional Information and a protracted review process if site conditions exceed the CSDRS used in the technical evaluations by the plant designer. The degree of risk is lower for sites that are not within, or near, known areas of active geologic processes such as active faults, volcanic centers, crustal plate margins, zones of enhanced historic seismicity, etc.

\section{A-2.4 Evaluation Criteria}

A site may be classified "Acceptable Site" if site-specific ground motions are $<90 \%$ of RG 1.60 spectra.

A site may be classified "Site Requires Further Evaluation" if site-specific ground motions are $=90 \%$ to $110 \%$ of RG 1.60 spectra.

A site may be classified "Site Not Suitable" if site-specific ground motions are $>110 \%$ of RG 1.60 spectra in the initial assessment.

The SRP (NUREG-0800) describes types of ground motion analyses acceptable to the NRC staff for safety related SSCs.

\section{A-2.5 Evaluation}

\section{Acceptable Site}

\section{Site Requires Further Evaluation}

\section{Site Not Suitable}

\section{A-2.6 Discussion}

\section{A-2.6.1 Site Type}

The site under evaluation is located in a heavy industrial area along the west bank of the Mississippi River approximately 25 mi upstream of New Orleans, LA (River Mile 129.6). This area has undergone extensive regional and site-specific geology and seismology characterization and evaluation with respect to NRC seismic acceptance criteria for a nuclear power facility. Detailed geologic and seismic information for the immediate locality, surrounding area and region have been derived from a wide variety of geologic and topographic sources that include maps, remote sensing data, surface mapping, subsurface poring, geophysical surveys and laboratory tests. There is also seismic instrumentation in operation at the adjacent Waterford 3 nuclear facility. Further geologic and seismic information on the site can be found in Section 2.5.1 of Ref. SGM-5. 
The site under assessment is located almost entirely upon the natural levee of the Mississippi River on the outside (eroding) bend of the river. The land parcel is currently encompasses the Waterford 3 nuclear power plant site. Elevations across the Waterford 3 site range from near sea level in the southwest (the vicinity of Site 2 being assessed) to about $14 \mathrm{ft}$ msl near the river. The location is characterized as a deep soil site situated in a flat topography with extensive areas covered by water, swamp, or marsh. It is an area of relatively low seismicity although ground shaking because of distant, large magnitude earthquakes may play a factor.

\section{A-2.6.2 Seismic Ground Motion}

Section 2.5.2 of Ref. SGM-5 outlines the history and dynamic behavior of materials underneath the site during prior earthquake events. According to this information, no unrelieved residual stresses exist in the unconsolidated foundation materials of the site nor are there any materials which could be unstable because of mineralogy. Earthquakes are generally randomly distributed within the region and are not typically identified with any specific tectonic structure.

Section 2.5.2.6 of Ref. SGM-5 details an analysis of the seismic wave transmission characteristics of the site, which was performed to support NRC licensing of Waterford 3. After considering the minimum accepted ground acceleration values as stipulated in 10 CFR 100, Appendix A (Ref. SGM-1) and coupling that information with the seismic history of the site and regional tectonic province, it was concluded that the selection of the SSE for the Waterford 3 facility should not be based on a historical seismic event but rather a hypothetical intensity VI MM earthquake with an epicenter adjacent to the site. This translated into a horizontal surface acceleration of $0.06 \mathrm{~g}$. The Waterford 3 plant was designed for a maximum horizontal ground surface acceleration of $0.10 \mathrm{~g}$. This is a very conservative assumption upon which to base further analysis because it is approximately double the maximum acceleration appropriate for the maximum earthquake which has actually occurred in this tectonic province during the last 250 years.

An operating basis earthquake (OBE) is an earthquake that could be expected to affect a site nuclear reactor but for which the plant power production equipment is design to remain functional without undue risk to public health and safety. Section 2.5.4.9 of Ref. SGM-5 summarizes the earthquake design basis for Waterford 3. Seismic analysis using the "synthetic" geologic record derived from the hypothetical earthquake yielded a postulated OBE scenario having a peak horizontal acceleration of $0.05 \mathrm{~g}$ and a peak vertical acceleration of $0.033 \mathrm{~g}$. These peak accelerations, with an indicated probability of occurrence at 2.6 percent over the 40-year life of the Waterford 3 plant, are one-half of the corresponding peak SSE accelerations.

Section 3.7 of Ref. SGM-5 considered the seismic design of the Waterford 3 plant. It modeled design response spectra using a maximum acceleration of $0.10 \mathrm{~g}$ for the SSE and a $0.05 \mathrm{~g}$ for the OBE for an earthquake with a maximum duration of 20 seconds. Although the resulting spectra was developed in a manner slightly different from the recommendations contained in NRC guidance (Ref. SGM-3), all seismic loads calculated using the analysis were found to be less than the corresponding loads set forth in plant component design specifications. Therefore, considering the ground motion presumptions and analysis presented in the Waterford 3 seismic evaluation and inferring those results against the more recent NRC seismic acceptance criteria that are specified in Section A-2.4 of this report, it is estimated that Site 2 will meet existing NRC seismic qualification standard expectations as they might be applied to a co-located HTGR facility.

\section{A-2.7 Risk Mitigation}

A great deal of high quality seismic information derived from a variety of sources has been compiled and analyzed in conjunction with the adjacent Waterford 3 nuclear facility. Because Waterford 3 seismic 
information can be further analyzed with a high degree of confidence, the risks of encountering influential but unknown seismic ground motion factors is considered relatively low.

Despite the high level of seismic characterization that exists for the area, the risks associated with under-prediction and/or poor characterization of the seismic conditions with respect to the specific design aspects of an HTGR can be reduced by:

- Examining the robust database of existing information relating to the Waterford 3 site and validating its contents and conclusions against the latest information available from topical and regional seismic experts

- Use of conservative assumptions for initial ground motion modeling and analysis and comparing it against the criteria set forth in an HTGR design

- Confirmatory field reconnaissance of the region and the specific site under consideration

- Performing confirmatory site-specific geologic, geophysical, and geotechnical tests to reevaluate and confirm existing understandings of seismic site response, dynamic properties, and ground failure potential.

\section{A-2.8 References}

SGM-1: $\quad 10$ CFR Part 50, "Licensing of Production and Utilization Facilities," Appendix A, "General Design Criteria for Nuclear Power Plants."

SGM-2: 10 CFR Part 100, "Reactor Site Criteria."

SGM-3: $\quad$ U.S. Nuclear Regulatory Commission, Regulatory Guide 1.60, "Design Response Spectra for Seismic Design of Nuclear Power Plants."

SGM-4: $\quad$ NUREG/CR-0098, "Development of Criteria for Seismic Review of Selected Nuclear Power Plants."

SGM-5: "Waterford 3 Final Safety Analysis Report," Revision 301 (09/07). 


\section{A-3. Health and Safety/Geology, Seismology and Geotechnical Engineering/Global Geohazards}

\section{A-3.1 Description}

A global geohazards assessment involves evaluation of the potential for surface deformation at or through the plant site as the result of active geologic processes. This includes fault displacement and tectonic surface deformation, subsidence (induced by groundwater withdrawal or mining), karst/dissolution, mechanically weakened zones (shear zones), liquefaction, irregular weathering, slope failure (landslides), unstable geologic deposits, and volcanism. The geohazard potential of an area is assessed by compiling and reviewing existing geoscience data and remote imagery, followed by geologic reconnaissance (ground and aerial) and site subsurface exploration. The risk and hazard assessment associated with geohazards are normally qualitative during a site screening study. However, a more quantitative evaluation of geohazards for Site 2 is available through previous efforts performed in support of the neighboring Waterford 3 nuclear power plant (Ref. GGH-1).

With respect to geologic processes, those structures or phenomena that show evidence of activity within the Quaternary geologic period (past 1.8 million years) are considered to be potentially active structures that require additional investigation. The NRC formally defines capable structures as those with evidence of activity once in the past 35,000 years or with evidence of recurring activity within the past 500,000 years (Ref. GGH-2 and GGH-3). The typical approach with regards to geohazards is avoidance rather than mitigation. Avoidance is preferred because some geohazards such as active fault displacement cannot be reasonably mitigated, would require prohibitive characterization/mitigation costs, and pose a major licensing risk.

Regulatory Guide 1.208, Appendix C (Ref. GGH-2) states that in general, any tectonic deformation at the earth's surface within the site area $(5 \mathrm{mi})$ requires detailed examination to determine its significance. Potentially active tectonic deformation within the seismogenic zone beneath a site will have to be assessed using geological, geophysical, and seismological methods to determine its significance. Engineering solutions cannot always demonstrate adequacy for mitigating the effects of permanent ground displacement phenomena such as surface faulting or folding, subsidence, or ground collapse. Sites that have a potential for fault rupture at or near the ground surface and associated deformation should be avoided. Therefore, site locations that are within $25 \mathrm{mi}(40 \mathrm{~km})$ of a tectonic structure that has exhibited (or have the potential to exhibit) surface displacement or deformation should be avoided if possible. If such a site is being considered, it must be determined through detailed investigations whether the tectonic structure is capable. More extensive investigation will be needed for any faults or other tectonic structures located within $5 \mathrm{mi}(8 \mathrm{~km})$ of a site to determine if they are capable tectonic sources. Accordingly, sites without such structures are favored.

Both nontectonic and tectonic deformation can pose a substantial hazard to a nuclear plant. But there are likely to be differences in the approaches used to resolve the issues raised by the two types of phenomena. Therefore, nontectonic deformation should be distinguished from tectonic deformation at a site. Nontectonic deformation is distortion of surface or near-surface soils or rocks that is not directly attributable to tectonic activity, such as features associated with subsidence, karst terrain, glaciation or deglaciation, and growth faulting. The nature of faults related to collapse features can usually be defined through geotechnical investigations and can either be avoided or, if feasible, adequate engineering solutions can be provided. Glacially induced faults generally do not represent a deep-seated seismic or fault displacement hazard because the conditions that created them are no longer present. Large, naturally occurring growth faults as those found in a coastal plain can pose a surface displacement hazard, even though offset most likely occurs at a much less rapid rate than that of tectonic faults. They are not 
regarded as having the capacity to generate damaging vibratory ground motion and can often be identified and avoided in siting (Ref. GGH-2).

\section{A-3.2 Importance}

General Design Criterion 2, "Design Bases for Protection Against Natural Phenomena," of Appendix A, "General Design Criteria for Nuclear Power Plants," to 10 CFR Part 50, "Licensing of Production and Utilization Facilities" (Ref. GGH-4), requires that SSCs important to safety be designed to withstand the effects of natural phenomena such as earthquakes and geologic hazards, without loss of capability to perform their safety functions. Geohazard-related surface deformation or movements can pose an unacceptable risk to the continued operability of safety related SSCs. 10 CFR Part 100, Section 100.23, "Geologic and Seismic Siting Criteria" (Ref. GGH-3) defines criteria for evaluating the suitability of a proposed site based on consideration of geologic, geotechnical, geophysical, and seismic characteristics of the proposed site. The presence of geohazards or Quaternary-active geologic structures are identified and compiled on regional and local maps that are typically in a geographic information system (GIS) database. Particular focus should be given to any geohazards or Quaternary structures within each of three areas defined by circles drawn around the site using radii of $25 \mathrm{mi}(40 \mathrm{~km})$ [site vicinity], $5 \mathrm{mi}(8 \mathrm{~km})$ [site area], and $0.6 \mathrm{mi}(1 \mathrm{~km})$ [site location].

Guidelines for evaluation of surface deformation geohazards are presented in RG 1.208 "A Performance-Based Approach to Define Site-Specific Earthquake Ground Motion” (Ref. GGH-2). Additional guidance related to characterization of geohazards and potential adverse site conditions is provided in RG 1.132 "Site Investigations for Foundations of Nuclear Power Plants" (Ref. GGH-5), RG 1.198 "Procedures and Criteria for Assessing Seismic Soil Liquefaction at Nuclear Power Plant Sites" (Ref. GGH-6), and RG 4.7 “General Site Suitability Criteria for Nuclear Power Stations" (Ref. GGH-7).

The NRC's SRP, Section 2.5.3, "Surface Faulting" (Ref. GGH-8), and Section 2.5.4, "Stability of Subsurface Materials and Foundations," provides additional insight as to areas of review by the NRC staff.

\section{A-3.3 Risk}

The possible presence of geohazards must be reviewed to determine the potential risk for the safety related SSCs in any nuclear power plant. Regulatory documents do not define exclusionary criteria for geohazards/surface deformation but rather suggest avoidance and detailed characterization of potential geohazards and Quaternary geologic structures. Nuclear plant licensing documents provide performance criteria with respect to plant foundation stability and settlement that can be used to compare against estimated magnitudes of surface deformation associated with a geohazard. However, characterization of potential magnitudes of surface deformation associated with a geohazard typically has substantial uncertainty and may require very extensive, expensive, and long-duration field and office studies. Regulatory review schedules may be significantly extended if geohazard characterization and mitigation is required.

Final NRC acceptance of the site may also be jeopardized by unresolved geohazards. For example, it is stated in NUREG-0800 (Ref. GGH-8) that "It is important to note that no commercial nuclear power plant has ever been constructed on a known capable tectonic deformation feature, and it is questionable whether it may be feasible to design for surface or near-surface tectonic displacements with any degree of confidence that safety-related plant features would remain intact and functional if displacements were to occur. Consequently, it is NRC policy to recommend that any site determined, based on results of detailed fault investigations, to lie on a surface or near-surface tectonic structure capable of displacement be prudently relocated to an alternate site by the applicant." A significant licensing risk is taken on for any site that is potentially impacted by geohazards/surface deformation, even if detailed investigations and 
analyses demonstrate that potential magnitudes of deformation are acceptable. Therefore, the recommended siting approach may be to avoid areas where regional and local mapping show the presence of tectonic deformation features.

\section{A-3.4 Evaluation Criteria}

A site may be classified "Acceptable Site" if no identified or suspected geohazards are within $25 \mathrm{mi}$ $(40 \mathrm{~km})$ of the site.

A site is classified "Site Requires Further Evaluation" if there are identified or suspected geohazards between within $25 \mathrm{mi}(40 \mathrm{~km})$ of the site.

A site may be classified "Site Not Suitable" if significant tectonic geohazards are identified on the site or within a 5-mile $(8-\mathrm{km})$ radius of the site.

NUREG-0800 describes the expected data sources and level of investigation and evaluation for screening of geohazards that are acceptable to the NRC staff for site evaluation. As described previously, avoidance rather than mitigation of geohazards/surface deformation is preferred.

For screening purposes, potential geohazards are identified and compiled on regional and local maps in a consistent approach as specified in RG 1.208, (Ref. GGH-2), including, as appropriate, GIS-based maps of the $25 \mathrm{mi}(40 \mathrm{~km}), 5 \mathrm{mi}(8 \mathrm{~km})$, and $0.6 \mathrm{mi}(1 \mathrm{~km})$ radii around Site 2. For identified and mapped geohazards, brief descriptive narratives are developed that summarize the hazard/feature, define its characteristics and potential hazard, and describe potential additional work for further characterization, if needed. All of these screening data were available in the NRC licensing documentation (Ref. GGH-1) that was developed for the neighboring Waterford nuclear facility.

\section{A-3.5 Evaluation}

\section{$\bigotimes$ Acceptable Site}

\section{Site Requires Further Evaluation}

\section{Site Not Suitable}

\section{A-3.6 Discussion}

\section{A-3.6.1 Site Type}

The site being evaluated is located in the southern portion of the Gulf Coastal Plain physiographic province. The parcel rests on the natural levee of the Mississippi River on the outside (eroding) bend of the river. The site is characterized as a deep sedimentary soil site situated in a flat topography with extensive areas covered by water, swamp, or marsh. It is adjacent to the Waterford 3 facility, an existing operating nuclear power plant already licensed by the NRC.

\section{A-3.6.2 Global Geohazards Analysis}

Section 2.5 of Ref. GGH-1 provides a description of the geological characteristics important to evaluating potential geohazards at the considered site. Sections 2.5.1.1 and 2.5.1.2 of Ref. GGH-1 summarize in great detail the physiography, geologic history, stratigraphy, and structural geology of the surrounding area and site, respectively. The information was sourced using available geologic literature, structural maps, remote sensing data, subsurface borings, geophysical reflection/refraction surveys, geophysical logs, and laboratory tests. 
Based on the information provided above, the unconsolidated sedimentary thickness beneath the site is estimated to be over 40,000 ft and lies above crystalline basement rock. Regionally, these sediments are not subject to stress buildup with formations of deformational zones or other structural weaknesses. No unrelieved residual stresses exist in the unconsolidated foundation materials around the site. No materials exist that could be unstable because of mineralogy. No zones of alteration or irregular weathering exist in the site area. There is no cavernous or karst terrain in the area nor is it evident that volcanic activity would be a consideration at this time.

The potential for geologic faulting has been thoroughly investigated in the area of Site 2 . The geologic structures which are known to exist in the vicinity are nontectonic structures typically associated with salt and clay mobilization and growth faults that were developed in thick sedimentary sequences. Regionally, faulting is known to exist as a result of the coastal depositional environment. As the very deep deposits consolidate with time and creep toward the ocean in a slope-failure type mechanism, faulting occurs in a pattern generally parallel with the coastline because of the differential settlement resulting from the varying depths of deposit becoming deeper toward the ocean. This action causes "growth faults" to occur that propagate from several thousand feet deep upward toward the surface.

Surface deformation or subsidence has been identified across the region. The subsidence may be because of growth faults, related to salt dome mines, attributed to compression of the very thick coastal depositional environment, or may be associated with groundwater withdrawal, or a combination of these effects. Subsidence because of faulting occurs as differential movement occurs across the fault and eventually, the subsidence propagates to the ground surface near the fault-line. Growth faults are known to exist across much of the coastal area (Ref. GGH-1, Section 2.5.1.1.4) but they are often difficult to detect from the surface. Growth faults are also often associated with salt domes. Salt dome mine subsidence occurs because of the removal of salt from the formation which results in vast caverns that may either be filled with fluids or gases to maintain internal mine pressures for integrity, reducing the likelihood of collapse.

Information presented in Section 2.5.1.3.5(e) of Ref. GGH-1 indicates the prospect of regional subsidence at Site 2 from mineral extraction activity (salt and sulfur) is low. Geologic and geophysical data indicate that no salt dome exists in the area with the exception of two deep-seated domes (deeper than 9,500 ft) which are between 5 and $7 \mathrm{mi}$ distant. Subsidence associated with removal of salt, sulfur, or the mineralization of the caprock which overlies the salt on most domes is not a site related problem.

The principal subsidence mechanisms that operate in the region result from petroleum production, groundwater withdrawal, gas production, and crustal movement. Section 2.5.1.3 of Ref. GGH-1 acknowledges that the southern Gulf Coast Plain is an area of extensive petroleum reserves and withdrawal. Numerous oil and gas test wells have been drilled in the vicinity of Site 2 but most were dry and never put into production. The closest petroleum production was one-half mile west of the site. That well was abandoned in 1947. The closest gas producing well is located $2 \mathrm{mi}$ distant. The potential for man-induced subsidence at the site from this type of fluid withdrawal is low. Regional subsidence, mostly attributable to groundwater extraction, was also determined insufficient to affect any structure or series of structures at the site (Ref. GGH-1, Section 2.5.1.3.4.)

Slope failure does not appear to be a consideration for this site. However, if significant amounts of fill are placed as part of construction of the facility, slope failure should be considered.

\section{A-3.7 Risk Mitigation}

A great deal of Site 2 global hazard information is already available through investigations and analysis previously conducted in connection with the Waterford 3 plant. The risk associated with geohazards and surface deformation can be further reduced by (1) examining the robust database of 
existing information concerning the locale and querying topical and regional experts about any recent discoveries or new insights that may have evolved; (2) using conservative assumptions regarding activity and consequences for initial evaluations of potential geohazard/surface deformation sources;

(3) performing confirmatory geologic aerial and field reconnaissance in the site region and location to confirm the veracity of existing information; and (4) obtaining additional site-specific geologic, geophysical, and geotechnical information to evaluate site geologic conditions and subsurface conditions. Much of this information is already available for the site being considered in the documentation that was used to develop Section 2.5 of Ref. GGH-1.

Certain geohazards may be mitigated through design decisions, once sufficient information has been considered for site-specific geohazards. The existing body of Waterford 3 site-specific information catalogued in Ref. GGH-1 can be relied upon to reasonably support many HTGR design decisions. Based on the information set forth in Ref. GGH-1 and the known conceptual design attributes of the HTGR, the site was deemed acceptable for purposes of this screening assessment. Additional research, localized exploration, and evaluation against final plant design will be necessary to further assess and confirm site suitability and mitigation of potential hazards for an HTGR co-located facility.

\section{A-3.8 References}

GGH-1. "Waterford 3 Final Safety Analysis Report,” Revision 301 (09/07).

GGH-2. U.S. Nuclear Regulatory Commission, Regulatory Guide 1.208, “A PerformanceBased Approach to Define Site-Specific Earthquake Ground Motion.”

GGH-3. 10 CFR Part 100, "Reactor Site Criteria."

GGH-4. 10 CFR Part 50, "Licensing of Production and Utilization Facilities," Appendix A, "General Design Criteria for Nuclear Power Plants."

GGH-5. U.S. Nuclear Regulatory Commission, Regulatory Guide 1.132, "Site Investigations for Foundations of Nuclear Power Plants."

GGH-6. U.S. Nuclear Regulatory Commission, Regulatory Guide 1.198, "Procedures and Criteria for Assessing Seismic Soil Liquefaction at Nuclear Power Plant Sites."

GGH-7. U.S. Nuclear Regulatory Commission, Regulatory Guide 4.7, "General Site Suitability Criteria for Nuclear Power Stations."

GGH-8. U.S. Nuclear Regulatory Commission, NUREG-0800, Section 2.5.3, "Surface Faulting," and Section 2.5.4, "Stability of Subsurface Materials and Foundations." 


\section{A-4. Health and Safety/Hydrology/Flooding}

\section{A-4.1 Description}

Safety related SSCs for a new candidate nuclear power plant site must be designed to withstand the worst flooding caused by an appropriate combination of several hypothetical events. The NRC requires that an application for a license to construct and operate a nuclear facility include evaluation of hypothetical worst case flooding scenarios. The hypothetical events include, but are not limited to: flood potential from streams, reservoirs, adjacent watersheds, and site drainage, including (1) the probable maximum water level from a stream flood, surge, seiche, combination of surge and stream flood in estuarial areas, wave action, or tsunami (whichever is applicable and greatest), and (2) the flood level resulting from the most severe flood wave at the plant site caused by an upstream or downstream landslide, dam failure, or dam breaching resulting from a hydrologic, seismic, or foundation disturbance. The effects of superimposing the coincident wind-generated wave action on the applicable flood level should be discussed and evaluated. The potential for flooding at the facility may involve evaluation of any or all hypothetical events or various combinations of these events. If the surface water level for the design basis flood rises above the maximum allowable flood elevation specified by the reactor technology vendor, additional flood protection measures may be required.

This evaluation is of the potential for flooding of the land area within the owner controlled area and immediately adjacent land area of the Waterford 3 nuclear plant and potential risk because of flooding of safety related structures associated with a new nuclear facility located near this existing nuclear facility.

\section{A-4.2 Importance}

Nuclear power plants shall be designed to prevent the loss of capability to perform the required safety functions to achieve and maintain cold shutdown considering the most severe (design basis) flood conditions that may occur at a site. General Design Criterion 2, "Design Bases for Protection Against Natural Phenomena," of Appendix A, "General Design Criteria for Nuclear Power Plants," to 10 CFR Part 50, "Licensing of Production and Utilization Facilities," (Ref. SRS-6) states that nuclear power plant structures, systems, and components important to safety shall be designed to withstand the effects of natural phenomena such as floods, tsunami, and seiches without loss of capability to perform their safety functions. Flooding of the nuclear facility may pose an unacceptable risk to the continued operability of safety-related structures.

\section{A-4.3 Risk}

To evaluate the ability of the nuclear facility to withstand the worst-case flooding scenarios and combinations, the site elevation, plant layout and design, data, analyses and all flood-related factors must be considered. As stated above, if the surface water level for the design basis flood rises above the maximum allowable flood elevation specified by the reactor technology vendor, additional flood protection measures may be required. The inability to demonstrate sufficient flooding protection may result in changes in the design or other mitigation measures being imposed in the plant's technical specifications and in emergency procedures. In the extreme case, the rejection of the site for construction of a new nuclear plant may be warranted because of excessive flooding concerns.

In addition, the potential effects of groundwater withdrawal on plant subsidence and elevation of existing groundwater aquifers on plant construction and operation need to be considered. 


\section{A-4.4 Evaluation Criteria}

A flooding analysis is performed to estimate the preliminary probable maximum flood (PMF) water surface elevation along with an appropriate safety factor. In the case of the Waterford 3 site, such an evaluation has been performed and was as presented in Ref. SRS-5 and accepted by the NRC. The design and construction of an additional nuclear facility on the Waterford location would need to meet the acceptance criteria of the evaluation and conform to the established flood protection requirements.

The site is classified as "Acceptable Site" if the analysis indicates that the flood level elevation does not reach a maximum elevation, in the area where the plant is likely to be located, that is above that specified by the reactor technology vendor.

The site is classified as "Site Requires Further Evaluation" if the flooding level elevation is at or above the maximum flood elevation specified by the reactor technology vendor, in the area where the nuclear facility is likely to be located, and flood protection measures may be required.

The site is classified as "Site Not Suitable" if the flood level elevation is expected to be above the maximum flood elevation specified by the reactor technology vendor, and flood protection and mitigation measures are deemed impractical.

Regulatory Guide (RG) 1.102 (Ref. SRS-1) describes acceptable flood protection measures. It should be used in conjunction with RG 1.59 (Ref. SRS-2) and ANSI/ANS-2.8-1992 (Ref. SRS-3) to determine final site acceptability.

\section{A-4.5 Evaluation}

\section{Acceptable Site}

\section{Site Requires Further Evaluation}

\section{Site Not Suitable}

Site 2 is considered acceptable from a flood protection perspective in the context that acceptable flood analyses have been performed and suitable and effective flood protection design features and procedures have been developed for the existing facility. However, existing state and federal evaluations should be confirmed as currently applicable to a new reactor facility. Also, an updated review of Mississippi River flood control measures and structures that are maintained by the US Army Corps of Engineers should be performed to validate information relied upon in the development of flood protection measures at the site for application to a new nuclear facility.

\section{A-4.6 Discussion}

\section{A-4.6.1 Site Type}

The Waterford area that includes Site 2 is located on the west (right descending) bank of the Mississippi River near River Mile 129.6 above head of passes, approximately 25 mi upstream of New Orleans. The site area consists of over 3000 acres with approximately 7,500 ft of river frontage. The Waterford 3 plant uses a once-through Circulating Water System with the Mississippi River as a heat sink. The Component Cooling Water System serves as the ultimate heat sink and is designed to remove heat from the plant during normal operation, shutdown, or emergency shutdown.

The primary hydrologic feature with which the Waterford 3 plant interacts is the Mississippi River. The plant uses the river as a sink for water heat and is protected from river flooding, including the surge 
associated with the probable maximum hurricane (PMH), by levees adjacent to the plant and a series of upstream and downstream reservoirs, floodways, and diversion structures near the plant.

The following provides useful design information regarding the Waterford 3 plant that may inform HTGR designers. As discussed in Ref. SRS-5, Section 2.4.1, the top of the exterior walls (flood walls) of the Nuclear Plant Island Structure (NPIS) were surveyed in 1991 to be at El. $29.27 \mathrm{ft} \mathrm{msl}$. The design flood level of the NPIS is reduced to El. $29.25 \mathrm{ft} \mathrm{msl} \mathrm{from} \mathrm{El.} 30.0 \mathrm{ft} \mathrm{msl}$, a 9-inch difference because of the plant settling nine-inches during construction. The safety-related equipment housed within the NPIS is still protected from disastrous floods since the highest level the water will reach at the NPIS is El. $27.6 \mathrm{ft}$ $\mathrm{msl}$ in the most severe conditions.

\section{A-4.6.2 Flood Design Considerations}

As discussed in Ref. SRS-5, Section 2.4.2.2, various hypothetical hydrologic events and combinations of hydraulic events have been used to determine the design basis for flood protection for safety related equipment and facilities. The design basis considered and the methods used to determine them meet the recommendations of NRC RG 1.59 (Ref. SRS-2). The events considered in detail are:

- Probable Maximum Precipitation (PMP) Over the Plant Site. The effects of the PMP on the plant site and the plant proper are presented in Ref. SRS-5, Section 2.4.2.3.

- Levee failures during PMF and PMH at the mouth of the Mississippi River are presented in Ref. SRS 5, Section 2.4.3.

Failure of the levees adjacent to the plant site was analyzed for the high water levels resulting from the PMF in the Mississippi River and the US Corps of Engineers Hypo Flood - 52A in the river coincident with the PMH surge at the mouth of the river. The maximum water level resulting from the levee breach is associated with the case of the PMH surge at the mouth of the river and Hypo Flood $52 \mathrm{~A}$ in the river. This resulted in a maximum water level of $+25.4 \mathrm{ft} \mathrm{msl}$ at the north wall of the NPIS. Additional consideration of a hypothetical river stage of $30 \mathrm{ft}$ msl resulted in a maximum effective water level of $27.6 \mathrm{ft}$ msl. The details of these analyses are presented in Ref. SRS-5, Sections 2.4.3.7 and 2.4.5.6.

The low-lying land surrounding the site landward of the levees is part of the Mississippi River Delta Basin and provides adequate site drainage from potential site flooding.

\section{A-4.6.2.1 Probable Maximum Surge}

For sites along or near open coastal areas, RG 1.59 (Ref. SRS-2) may be used to estimate the probable maximum surge based on the probable maximum hurricane. The probable maximum surge data for coastal areas are provided in tables and figures in RG 1.59, Appendix C.

The effects of a hurricane surge passing through Barataria Bay are analyzed coincident with the PMP. The maximum still water level from this analysis is computed to be $+18.1 \mathrm{ft} \mathrm{msl}$. The maximum effective water level from hurricane-induced wind waves was computed to be $+23.7 \mathrm{ft} \mathrm{msl}$.

\section{A-4.6.2.2 Probable Maximum Flood}

A PMF at the nuclear facility is estimated using RG 1.59 (Ref. SRS-2) which describes methods for estimating the PMF for plants located on streams, along lakeshores, coastlines, and estuaries. The site under consideration is located along the Mississippi River, as described above. A potential cause of flooding in the Mississippi River Delta Basin is hurricane-induced surge flooding. Although the plant is approximately $60 \mathrm{mi}$ from the open coast, hurricane surges have historically flooded large portions of the Lower Mississippi River Delta area. 
The existing comprehensive flood control and navigation plan for the Mississippi River consists of a levee system along the main stem of the river and its tributaries in the alluvial plain, reservoirs on the tributary streams, floodways to receive excess flow from the river, and channel improvements such as revetment dikes, and dredging to increase channel capacity. This is further discussed in Ref. SRS-5, Section 2.4.1.

\section{A-4.6.2.3 PMF-Induced Levee Failure}

All safety related equipment at Waterford 3 is protected within the NPIS, which is flood-proof to $30 \mathrm{ft}$ msl. The site itself is protected from flooding from the Mississippi River by the levee, which has a crest elevation of $30 \mathrm{ft}$ msl opposite the plant. Since this is not a seismic Category I structure, flood conditions resulting from its failure must be considered. Further details of a PMF-induced levee failure are presented in Ref. SRS-5, Section 2.4.3.7.

In the event of a flood greater than the plant design flood (PDF), that part of the discharge exceeding the capacity of the Mississippi main stem levees would either be stored on floodplains following levee failure or passed to the Gulf of Mexico via the Atchafalaya River basin. It was also concluded that flooding of the site from the Atchafalaya River basin is not possible.

Site elevations vary from a maximum of $14 \mathrm{ft}$ msl on the north and west to a minimum of nearly seal level at the southeast corner of the plant area. It is estimated that the surge from a slow-moving PMH, crossing over the low-lying marshlands from the direction of Barataria Bay could exceed the plant grade of $17.5 \mathrm{ft}$ msl by $0.6 \mathrm{ft}$ for a brief period (Ref. SRS-5, Section 2.4.5.2). However, the coincidence of this event with a river flood greater than the PDF is not considered reasonably possible.

Site drainage characteristics because of flooding from coincident heavy precipitation and failure of the levee are discussed in Ref. SRS-5, Section 2.4.3. The drainage system is designed for a maximum rainfall intensity of $8.25 \mathrm{in} / \mathrm{hr}$.

\section{A-4.6.3 Potential Dam Failures, Seismically Induced}

As presented in Ref. SRS-5, Section 2.4.4, there are multiple flood control reservoirs upstream of the site. Although the combined storage of those reservoirs is considerable, the stream distance and resulting channel storage between the reservoirs and the plant site is considered to be great enough to attenuate any flood wave resulting from the failure of any of these reservoirs to a level below that resulting from the PMF, or a PMH at the mouth of the Mississippi River. The reservoirs are not in tandem. Therefore, the combined failure of all the reservoirs is not considered to be reasonable.

\section{A-4.6.4 Probable Maximum Surge and Seiche Flooding}

Probable maximum surge and seiche flooding is discussed in Ref. SRS-5, Section 2.4.5. The Mississippi Delta region of Louisiana is prone to high winds and flooding associated with hurricanes. Therefore, a PMH is hypothesized. The river stages with and without the effect of the PMH were determined as $28 \mathrm{ft} \mathrm{msl}$ and $24 \mathrm{ft} \mathrm{msl}$ respectively.

The predicted height of the PMH flood at the site is $+18.1 \mathrm{ft}$ msl, including PMP.

\section{A-4.6.5 Wave Action}

To determine the highest water level to be expected at Waterford 3 because of the PMH and the upstream flood, the wind setup and wave run-up because of the coincident local hurricane wind should be included. An analysis of wave action under various conditions is presented in Ref. SRS-5, Section 2.4.5.3, 
which concludes the plant is not threatened by wave action. The design of Waterford 3 safety related structures for protection against flooding and wave action is discussed in Ref. SRS-5, Section 3.4.

\section{A-4.6.6 PMH Induced Levee Failure}

As discussed in Ref. SRS-5, Section 2.4.5.6, the PMH is capable of producing a stage in the Mississippi River near the site that is 1-ft higher than the PMF, but only for a brief duration. Because of the likelihood of severe wave activity, however, levee failure adjacent to Site 2 must still be considered possible. Site flooding coincident with the arrival of the PMH surge in the river is not reasonably possible.

\section{A-4.6.7 Probable Maximum Tsunami Flooding}

As discussed in Ref. SRS-5, Section 2.4.6, occurrences of tsunamis are relatively rare in the Gulf of Mexico and Atlantic Ocean as compared to the Pacific Ocean. It is concluded that the Gulf Coast near the site will not experience any significant tsunami flooding. Any tsunami flooding effects that may be postulated will be minor in comparison to the hurricane surge flooding.

\section{A-4.6.8 Ice Effects}

The appearance of ice on the lower reach of the Mississippi River is a rare occurrence, especially below the vicinity of Baton Rouge. The mild to moderate quantity of drift ice observed in this region has an estimated frequency of occurrence of two or three times in the past 100 years, and has never resulted in ice jams that might have caused some visible damage or impaired river navigation.

As concluded in Ref. SRS-5, Section 2.4.7, Site 2 will not experience any difficulties or problems that might arise from ice flooding or ice flow blockage.

NOTE: The following sections A-4.6.9 and A-4.6.11-A-4.6.15 discuss low water conditions that may not apply to the HTGR design, but are provided for information.

\section{A-4.6.9 Channel Diversions}

Measures to prevent an occurrence of Mississippi River channel diversions and potential consequences of a channel diversion event are presented in Ref. SRS-5, Section 2.4.9. As explained in Ref. SRS-5, Section 2.4.11, the component cooling water system is the ultimate heat sink for the plant, and the circulating water system is not necessary for dissipating heat during an emergency shutdown condition.

\section{A-4.6.10 Flooding Protection Requirements}

Flood protection requirements for Waterford 3 are described in Ref. SRS-5, Section 2.4.10. All safety related equipment is housed within the NPIS. The NPIS is a reinforced concrete box structure with solid exterior walls and is flood protected up to El. $+30.0 \mathrm{ft} \mathrm{msl}$. For installation of HTGR modules at this site, comparable design considerations to protect against the effects of flooding would have to be incorporated.

\section{A-4.6.11 Low Water Consideration}

As discussed in Ref. SRS-5, Section 2.4.11, the intake structure for Waterford 3 will not be required to operate under probable minimum low flow conditions since it is not safety-related. 


\section{A-4.6.12 Future Controls}

As noted in Ref. SRS-5, Section 2.4.11.4, the Louisiana Department of Public Works has conducted an investigation to determine the state's projected surface water requirements to the year 2020. Their study concludes that the Southeast Sector of Louisiana has and will continue to have the maximum surface water requirements for all years.

\section{A-4.6.13 Plant Requirements}

Plant water use requirements are presented in Ref. SRS-5, Section 2.4.11.5. There are normally no safety related water requirements from the Mississippi River for Waterford 3. The Component Cooling Water System utilizes dry-wet cooling tower combinations as the ultimate heat sink (UHS), as described in Ref. SRS-5, Section 9.2.5. Mississippi River water may be uses as a source of makeup water to the wet cooling tower basins following a tornado event.

\section{A-4.6.14 Heat Sink Dependability Requirements}

The design of Waterford 3 is consistent with applicable recommendations of Regulatory Guide 1.27 (Ref. SRS-4). The UHS utilizes replenishment from an alternative water supply (onsite water sources and/or Mississippi River water) to ensure cooling capacity for 30 days and beyond in response to a design basis tornado event. Ref. SRS-5, Section 9.2.5 further discusses the UHS. This is also discussed in Ref. SRS-5, Section 2.4.11.6.

\section{A-4.6.15 Dispersion, Dilution, and Travel Time of Accidental Releases of Liquid Effluents in Surface Waters}

The possibility of an accidental release of radioactive effluents by Waterford 3 reaching a surface water body is virtually nonexistent. The details of this conclusion are presented in Ref. SRS-5, Section 2.4.12.

\section{A-4.6.16 Groundwater}

Overall groundwater considerations at the Waterford location are discussed in Ref. SRS-5, Section 2.4.13 and 2.5.4 and in Section A-1.6.3 of Appendix A to this report.

\section{A-4.7 Risk Mitigation}

The flood protection measures, as suggested in RG 1.59 (Ref. SRS-2) and RG 1.102 (Ref. SRS-1), may be considered. If the nuclear facility safety related structures are at or below the design basis flood elevation, the facility may be elevated by fill. However, the effects of any fill required to protect the facility from flooding on other aspects of the site must be considered.

Risk can also be mitigated by other flood protection measures that can be taken to protect safety related SSCs from the adverse effects from the flooding, such as design features that restrict openings to the safety related structures to elevations below the design basis flood elevation of $+30 \mathrm{ft} \mathrm{msl}$, use of water-tight doors for building entry ways potentially below the design basis flood elevation, etc. Additionally, emergency procedures may be used as a way to mitigate flooding of safety related SSCs as described in RG 1.59 and RG 1.102 .

Conclusions reached for the evaluation of the Waterford 3 site regarding the adequacy of design for protection against severe natural phenomena associated with maximum probable hurricane, maximum probable precipitation, ice effects, breaches of nearby levees, and maximum probable flood, as described in Ref. SRS-5, have been based in part on evaluations performed in the early to mid-1970s. These 
evaluations should be reconfirmed as applicable to the installation of HTGR modules at Site 2. In addition, Ref. SRS-5 provides descriptions of various engineered and natural features on the Mississippi River that contribute to site flood protection (diversion structures, floodways, levees, etc.). These features are maintained by the US Army Corps of Engineers. The continued adequacy of these features for flooding mitigation and the need for any new or proposed features should also be evaluated or reconfirmed for the installation of HTGR modules on Site 2.

\section{A-4.8 References}

SRS-1: U.S. Nuclear Regulatory Commission, Regulatory Guide 1.102, "Flood Protection for Nuclear Power Plants," Revision 1, September 1976.

SRS-2: U.S. Nuclear Regulatory Commission, Regulatory Guide 1.59, "Design Basis Floods for Nuclear Power Plants," Revision 2, August 1977.

SRS-3: ANSI/ANS-2.8-1992, "Determining Design Basis Flooding at Power Reactor Sites," July 28, 1992.

SRS-4: U.S. Nuclear Regulatory Commission, Regulatory Guide 1.27, "Ultimate Heat Sink for Nuclear Power Plants," Revision 2, January 1976.

SRS-5: “Waterford 3 Final Safety Analysis Report,” Revision 301 (09/07).

SRS-6: U.S. NRC, 10 CFR 50, "Licensing of Production and Utilization Facilities," Appendix A, "General Design Criteria." 


\section{A-5. Health and Safety/Hydrology/Water Availability}

\section{A-5.1 Description}

This evaluation considers potential impacts pertaining to water availability in an industrial setting and identifies factors that may potentially challenge site suitability for the construction and operation of an HTGR facility, or pose hazards and potential challenges to the HTGR design. As discussed in NRC RG-4.7, "General Site Suitability Criteria for Nuclear Power Stations," water supply requirements for nuclear power plants must be sufficiently available for cooling during plant operation and normal shutdown, for the ultimate heat sink, and for fire protection. The use and consumption of water at potential sites for normal operation limitations imposed by existing laws are governed by water use plans of cognizant water resource planning agencies and other statutory requirements and policies.

Multiple areas on the Site 2 property were considered as potential locations for the HTGR facility. For purposes of this assessment, the close proximity of all the potential locations on the Site 2 property make the distinction or differences in the water availability and the potential challenges to HTGR facility design essentially negligible. This assessment, therefore, does not present individual analyses for each area on the site. Instead, this assessment presents a single analysis that applies equally to all of the site areas.

\section{A-5.2 Importance}

Depending on the specific plant design, nuclear power plants may require reliable sources of water for turbine generator steam condensation, service water, emergency core cooling systems, and other functions. According to the NRC's Environmental Standard Review Plan, NUREG-1555, "Standard Review Plans for Environmental Reviews for Nuclear Power Plants," a detailed and thorough description of water use during plant operations is essential for evaluating potential impacts to the environment that may result from plant construction or operation. Because water quality and water supply are interdependent, changes in water quality must be considered simultaneously with possible changes in water supply.

10 CFR 100.21, "Non-seismic siting criteria," states that physical characteristics of the site, including hydrology, must be evaluated and site parameters established such that potential threats from physical characteristics will pose no undue risk to the type of facility proposed to be located at the site. $10 \mathrm{CFR}$ 100.23 "Geologic and seismic siting criteria," states that siting factors for other design conditions that must be evaluated include a cooling water supply. Each applicant shall evaluate all siting factors and potential causes of failure that may affect the design and operation of the proposed nuclear power plant.

\section{A-5.3 Risk}

The site water supply characteristics during times of low-flow, corrected for other use allocations as projected into the period of facility operations, must be compared with the design basis facility water consumption rate. Water use and consumption must be compatible with existing water use plans. In the absence of an existing water use plan, the effect of plant water usage on other water users is evaluated, considering flow or volume reduction and the resultant ability of all users to obtain adequate supply and to meet applicable water quality standards.

Sufficient quality and quantity of water supply data is necessary for the acceptance of the nuclear power plant application. High quality data from publicly available local, state, and federal sources, as well as any available site-specific data, may be used to initially assess the site. Insufficient quality or quantity of data may result in increased investments of time and money to generate the data or in the rejection of the site for the nuclear power plant application. 


\section{A-5.4 Evaluation Criteria}

A site may be classified as "Acceptable Site" when it is shown to have adequate water resources to meet or exceed plant usage expectations during low-flow conditions based on conservative assumptions without exceeding existing water withdrawal restrictions or affecting the ability of other water users to meet their water needs.

A site may be classified as "Site Requires Further Evaluation" when alternative water use strategies or mitigation measures would be necessary to meet water availability requirements for all users. Potentially challenged sites may also require additional procurement of water rights or additional study to assure that other users are not adversely impacted.

A site may be classified as "Site Not Suitable" when the capacity of available water resources is exceeded and it is not reasonable to mitigate impacts.

\section{A-5.5 Evaluation}

\section{Acceptable Site}

Site Requires Further Evaluation

\section{Site Not Suitable}

\section{A-5.6 Discussion}

\section{A-5.6.1 Site Type}

This evaluation was conducted with the purpose of recognizing potential site hazards pertaining to water availability at an existing commercial light water nuclear power plant located in close proximity to major industrial facilities and identifying factors that may potentially challenge the design, construction, and operation of an HTGR plant. Evaluations of water quality and supply that have been performed for the existing nuclear plant apply equally to siting an HTGR.

\section{A-5.6.2 Evaluation}

\section{A-5.6.2.1 Site 2 Water Resources}

For the evaluation of water availability, the background setting of all potential siting locations on Site 2 are considered equivalent (Ref. WAV-1). Each area is assumed to have essentially equal access to water from the Mississippi river, St. Charles Parish, and groundwater (if supply from aquifers is pursued). Access to the river will require construction of intake and return piping over flood protection levees similar to those that are in current operation at the existing nuclear plant. This will require obtaining permits from the US Army Corps of Engineers. This is not judged to impact site suitability.

Neither the existing fossil plants nor the existing commercial nuclear plant adjacent to Site 2 use groundwater as a water supply source. Other than condenser cooling water, which is pumped from and returned to the Mississippi River, all water used at the site is purchased from the local water district (St. Charles Parish). Based on analyses performed for the existing nuclear power plant, groundwater supply sources in the site area may be limited by availability and quality (Ref. WAV-2).

All makeup water for the existing nuclear plant systems is purchased from St. Charles Parish. Mississippi River water is used solely for main condenser cooling (circulating water system). Water purchased from St. Charles Parish is treated on site to achieve the required chemistry specifications for 
use in plant systems. Once treated, sufficient quantities are stored on site for use as needed. The only continuous demand on the St. Charles Parish water supply is for site personnel potable water usage (Ref. WAV-2).

It should be noted that at the time of this evaluation, only scoping estimates have been made of the volume or rate of consumption of raw water for cooling using HTGR technology. Cooling water usage is primarily dependent upon the design of the cooling system (i.e. once-through or closed) necessary to meet both plant needs and current regulatory requirements. Other service water cooling water requirements have not yet been determined; an increase of the condenser cooling water supply requirements of $10 \%$ has been applied to account for this water need. This evaluation assumes that the HTGR plant will be modular in design with four units. It is also assumed that the HTGR plant will not use groundwater or tap into existing aquifers but, as is done in the existing nuclear plant, all water will be obtained from the Mississippi River and the St. Charles Parish water supply.

Since the HTGR plant is intended to be designed to use only water from either the Mississippi River or the local water district as the primary water sources, an ample source is available and the site evaluation for water availability would be "Acceptable Site." However, if as the HTGR design evolves it is determined that water from groundwater aquifers is required, more study would be required to determine if an adequate water supply exists during all postulated conditions without impacting other users or causing ground subsidence. This would result in a site evaluation for water availability of "Site Requires Further Evaluation.”

\section{A-5.6.2.2 Potential Impacts of HTGR Plant Water Usage}

For this evaluation, it is assumed that the largest HTGR plant considered for this application will be implemented with full rated steam turbine generators. This will require a condenser flow rate of 210 million lbs/hr (Ref. WAV-1). Potable and fire protection water requirements are expected to be comparable to that required by the existing nuclear plant, a maximum of $10 \mathrm{gpm}$ and $360 \mathrm{gpm}$, respectively. The water requirements of the HTGR facility would be in addition to current usage of the existing nuclear power plant. In reality, some of the cooling water needs may be met by treated water or recycled water or condensate already within the Company's supply system, which would further reduce potential impacts.

\section{A-5.6.2.3 Additional Site Owner Needs}

The HTGR facility will convey steam to nearby facilities for industrial use (Ref. WAV-1). Water required for steam generation is not included in this evaluation since condensate will be returned to the HTGR plant after industrial use per the commercial agreement(s) established with the user(s).

\section{A-5.7 Risk Mitigation}

At Site 2, the Mississippi River provides an adequate cooling water supply for the main condenser (circulating water system). Based on the experience with the existing nuclear plant, the potable water supply from the local water district appears adequate to support operation of an HTGR facility.

\section{A-5.8 References}

WAV-1. INL/EXT-11-23282, "NGNP Project Evaluation of Siting a HTGR Co-generation Plant on an Operating Commercial Nuclear Power Plant," Revision 0, October 2011.

WAV-2. "Waterford 3 Final Safety Analysis Report,” Revision 301 (09/07), Section 2.4.13. 


\section{A-6. Health and Safety/Nearby Hazardous Activities}

\section{A-6.1 Description}

This evaluation identifies the proximity of nearby hazardous activities based on a 5-mile radius (this is the distance used in the analysis for Ref. NHA-1). Nearby transportation routes and potential hazardous facilities identified include airports, roadways, railways, pipelines, navigable water bodies, military facilities, and industry. Onsite storage of hazardous materials was also identified within this evaluation.

\section{A-6.2 Importance}

The federal regulations contained in 10 CFR 100 "Reactor Site Criteria" (Ref. NHA-7) set forth the requirements for siting a reactor. In particular, 10 CFR 100.20(b) requires that "the nature and proximity of man-related hazards (e.g., airports, dams, transportation routes, military and chemical facilities) must be evaluated to establish site parameters for use in determining whether a plant design can accommodate commonly occurring hazards, and whether the risk of other hazards is very low." Further, 10 CFR 100.21(b)(e) states that upon evaluation and the subsequent establishment of site parameters, the applicant would demonstrate that "potential hazards from such routes and facilities will pose no undue risk to the type of facility proposed to be located at the site."

Section 2.2.3 of NUREG-0800, "Standard Review Plan for the Review of Safety Analysis Reports for Nuclear Power Plants: LWR Edition" (Ref. NHA-2) requires an evaluation of potential accidents regarded as design-basis events using the criteria specified in Section 2.2.3 of NUREG-0800 for nearby hazards identified and for hazards associated with nearby transportation routes and military and industrial facilities. Section 6.4 of NUREG-0800 requires an evaluation of the habitability of the reactor control room based on hazards identified on the site and identified nearby hazards using the criteria for evaluation of control room habitability as specified in NUREG-0800, Section 6.4. Particular risks to be evaluated include (at a minimum):

- Toxic vapors or gases and their potential for incapacitating nuclear plant control room operators

- Overpressure resulting from explosions or detonations involving materials such as munitions, industrial explosives, or explosive vapor clouds resulting from the atmospheric release of gases (such as propane and natural gas or any other gas) with a potential for ignition and explosion

- Missile effects attributable to mechanical impacts, such as aircraft impacts, explosion debris, and impacts from waterborne items such as barges

- Thermal effects attributable to fires.

\section{A-6.3 Risk}

As stated in Sections 2.2.1 and 2.2.2 of the Standard Review Plan (Ref. NHA-2), collection and analysis of data pertaining to the identified parameters support the determination of whether design-basis events could have "potential consequences sufficiently serious to affect the safety of the plant to the extent that 10 CFR Part 100 guidelines could be exceeded." The inability to demonstrate sufficient design contingencies or provide assurance that the plant has adequate protection and can operate with an acceptable degree of safety in the event of an offsite accident involving hazardous materials, could result in the rejection of the application and/or the candidate site. 
Regulatory Position C.8 of RG 4.7, "General Site Suitability Criteria for Nuclear Power Stations" (Ref. NHA-3), specifies that the acceptability of a site based on nearby potential hazards would depend on establishing that:

- An accident at a nearby industrial, military, or transportation facility would not result in radiological consequences that exceed the dose specified in 10 CFR 50.34, or

- The accident poses no undue risk because it is sufficiently unlikely to occur (less than about $10^{-7}$ per year), or

- The nuclear power station can be designed so its safety will not be affected by the accident.

\section{A-6.4 Evaluation Criteria}

A site may be classified "Acceptable Site" when no hazardous sites are identified within $10 \mathrm{mi}$ $(16 \mathrm{~km})$ of the proposed plant site. (The Site 2 evaluation considered hazards within $5 \mathrm{mi}$ of the site.)

A site may be classified "Site Requires Further Evaluation" when hazardous sites and activities are identified within $10 \mathrm{mi}(16 \mathrm{~km})$ of the proposed plant site. (Although this evaluation included hazards out to $5 \mathrm{mi}$, it can be expected that these hazards would bound hazards identified between 5 and $10 \mathrm{mi}$ from Site 2.)

A site may be classified "Site Not Suitable" if unacceptable hazards are identified in the site vicinity; however this classification cannot occur at this initial screening level of evaluation. All identified nearby hazardous activities will require additional evaluation per SRP guidance. If the probability of an event and the consequences of the analyses exceed the defined thresholds, mitigation may still be possible.

\section{A-6.5 Evaluation}

\section{Acceptable Site}

$\bigotimes$ Site Requires Further Evaluation

\section{Site Not Suitable}

\section{A-6.6 Discussion}

\section{A-6.6.1 Site Type}

Site 2 is located within an area adjoining an existing operating nuclear power plant, It is therefore considered an existing nuclear power plant site. Site 2 is situated in an industrialized area.

\section{A-6.6.2 Nearby Explosive Hazards Analysis}

This section presents the results of a survey of the industrial and transportation facilities and military installations and operations within $5 \mathrm{mi}$ of Site 2 . Since the evaluation criteria designates that hazards within $10 \mathrm{mi}$ of the site be evaluated, further evaluation is necessary.

Transportation, storage, and use of some of the materials cited in Tables 2.2-3B through 2.2-3G and Table 2.2-5 from Ref. NHA-1 present a potential for explosions, fires, or releases of toxic gases. The hazards associated with chemicals transported or stored in quantity within $5 \mathrm{mi}$ of Waterford were evaluated to assure appropriate HTGR design consideration. Several sources present hazards that merit closer investigation.

The sources of hazards are: 
- River transport of gasoline along the shipping channel. As required by the US Army Corps of Engineers, Site 2 must be located at least 1,500 ft from the banks of the Mississippi River

- LPG shipments by truck passing the site at a closest distance of approximately 1,500 ft from Site 2

- Transport of hazardous material via railroad which has a line passing near the proposed site

- Nearby gas pipelines, LPG lines, and/or flammable stationary sources.

Additional information regarding these and other hazards is provided below.

\section{A-6.6.2.1 Evaluation of Transportation of Explosives and/or Flammables on the Mississippi River}

For river traffic, the transport of gasoline poses the most significant hazard for fires and explosions, and although by itself it does not pose a hazard exceeding the 10CFR50.67 standard, it may be taken to be the design basis accident issuing from the transportation of flammable and/or explosive cargo on the Mississippi River near the site. Various scenarios are evaluated in Section 2.2.3.1.1 of Ref. NHA-1. Distances used in the evaluation represent the Waterford 3 nuclear plant. Site 2 is expected to be located further from the river so impacts from river hazards would be proportionally less.

A worst case scenario determined that a gasoline detonation could generate a peak overpressure of $1.3 \mathrm{psi}$ at a distance of $1,200 \mathrm{ft}$. The reflected pressure is $2.7 \mathrm{psi}$, which is an acceptable overpressure for Waterford 3 safety related buildings. The HTGR site is further from the river (about 1,500 ft), so overpressure is likely to be less than these values.

The Mississippi River Channel passes approximately 1,200 ft north of the Waterford 3 NPIS. It is therefore concluded that missiles generated from an explosion of a 300,000 barrel ship cannot reach the NPIS with a large, destructive missile. The HTGR site is further from the river (about 1,500 ft) and thus a destructive missile is less likely to affect HTGR structures.

It should be noted that information contained in Ref. NHA-1 regarding river traffic requires confirmation for applicability to the HTGR installation.

\section{A-6.6.2.2 Transport of Explosives and/or Flammables by Truck}

Section 2.2.3.1.2 of Ref. NHA-1 contains an evaluation of accidents involving transport vehicles. A review of truck traffic reveals that the governing explosive and/or flammable event would arise from a remote and unlikely accident to an LPG tank truck on riverfront Route 18 at a critical distance of $462 \mathrm{ft}$ north, east, or west of the Waterford 3 NPIS. If a conservative estimate of $240 \%$ TNT (trinitrotoluene) equivalent is used, the resulting peak overpressure is 3.0 psi and a peak reflected overpressure is 6.5 psi. Since Site 2 is anticipated to be located further from this river frontage road, the peak overpressure for Site 2 would be smaller.

\section{A-6.6.2.3 Nearby Gas Pipelines and Storage}

Section 2.2.3.1.3 of Ref. NHA-1 contains an evaluation of nearby gas pipelines and storage. A review of the pipelines carrying flammable and potentially explosive materials, within a 5-mile radius of Waterford 3 reveals that the most hazardous line is most likely to be the Bridgeline 26-inch natural gas line. This line is located approximately $0.6 \mathrm{mi}(3,000 \mathrm{ft})$ from the Waterford 3 plant. This line is taken as the line for the design basis accident analysis because of the proximity of the gas line and the potentially high transport rate of flammable gas. If this pipeline ruptures and creates a detonable plume, such an explosion could create an overpressure of about 1.00 psi and a reflected overpressure of $2.1 \mathrm{psi}$ at the 
Waterford 3 site. Since the HTGR site is closer to these gas lines, the effects of an explosion would likely generate higher peak overpressures.

\section{A-6.6.2.4 Nearby Air Products Hydrogen Pipeline Project}

Section 2.2.3.1.3.4 of Ref. NHA-1 evaluated potential hazards from a nearby Air Products Inc. hydrogen pipeline project. The conclusion of the study was that the overpressure from an explosion on this hydrogen pipeline would be much less than $1.0 \mathrm{psi}$ for Waterford 3. Therefore, this value would not be bounding for Site 2 .

\section{A-6.6.2.5 Potential Hazards from Externally Generated Missiles}

Section 2.2.3.1.4 of Ref. NHA-1 evaluated potential hazards from externally generated missiles. Comparison of the Waterford 3 results and Electric Power Research Institute data (Ref. NHA-4) show that since all walls and roofs of safety related structures are at least two feet thick, and the concrete strength is at least 4,000 psi ( 28 day crush test), there is no danger of penetration and/or spalling of walls and roofs of safety related structures caused by missiles picked up by overpressure waves.

The range of a "rocketing" rail car that occurred in the accident in Laurel, Mississippi, was 1,100 ft, while small fragments had a maximum range of 1,600 ft. The reactor building and reactor support area for the HTGR facility are greater than 1,100 ft from the rail line (as shown in Figure 1). However, Site 2 is considerably closer to the railroad line than the Waterford 3 nuclear plant and within the ranges of fragments of the train accident in Laurel, Mississippi. Hence, more evaluation will be required regarding potential missiles from explosions in tank cars on the nearby railroad line (Section 2.2.3.1.4 of Ref. NHA1) to establish adequate levels of protection for the HTGR facility.

\section{A-6.6.2.6 Delayed Ignition of Flammable Vapor Clouds}

Section 2.2.3.2 of Ref. NHA-1 evaluated hazards from a delayed ignition of flammable vapor clouds. Under conservative assumptions, where no credit for attenuating factors is taken, the heat load on the wall from the propane vapor cloud ignition is $4.18 \times 10^{5} \mathrm{BTU} / \mathrm{hr}^{-\mathrm{ft}^{2}}=116.34 \mathrm{BTU} / \mathrm{sec}-\mathrm{ft}^{2}$, for the short duration of 7.44 seconds. This will cause surface skin-heating effects on the outside walls, but the short durations involved will not compromise the integrity of any safety related structure at the Waterford 3 plant. Other sources of flammable vapor clouds are considered to present lesser hazards because of greater distances from the site and the conservatisms of the propane vapor clouds analyzed.

\section{A-6.6.3 Toxic Chemicals - Stationary}

Section 2.2.3.3 of Ref. NHA-1 evaluated potential impacts from toxic chemicals stored or transported near the site. Materials cited in Tables 2.2-3B through 2.2-3G, 2.2-5, and 2.2-6 of Ref. NHA-1 indicate that there are several sources for release of toxic chemicals that have a potential for adversely affecting main control room habitability. Following guidance in Regulatory Guide 1.78 (Ref. NHA-6), consideration was limited only to those chemicals present within a 5-mile radius of the main control room air intakes. The calculations were performed for the entire range of meteorological conditions presented in Section 2.3 of Ref. NHA-1, and were based on main control room characteristics described in Section 6.4 of Ref. NHA-1.

Potential hazards posed by stationary sources of chlorine were evaluated at Waterford 3 by comparing such sources to the allowable quantities of chlorine and distances from the control room listed in Table 1 of Regulatory Guide 1.95 (Ref. NHA-5, this regulatory guide has since been withdrawn by the NRC). The stationary source of chlorine posing the greatest potential hazard is a tank on the site of Occidental Chemical Co. (Oxychem), which contains 400 tons of chlorine and is located 1,506 meters from the Waterford 3 control room. At this distance, the maximum allowable quantity calculated by log-log 
interpolation (for Type II control room), in accordance with the guidance of RG 1.95, is 685 tons. A 600 ton chlorine tank at a distance of 1,677 meters is also located at Oxychem; the maximum allowable quantity at this distance is 967 tons.

If the control room is habitable under meteorological conditions occurring not less than $95 \%$ of the time for the given compass direction, the given stationary sources, other than chlorine, evaluated in Ref. NHA-1 do not pose a hazard. The HTGR control room design will need to consider the results of a sitespecific toxic gas analysis.

\section{A-6.6.4 Toxic Chemicals - Transient}

Section 2.2.3.3.5 of Ref. NHA-1 evaluated potential accidents from transient chemicals. The analyses showed that the overall probability that toxic chemicals frequently transported in the vicinity of Waterford 3 could pose a potential hazard to the Waterford 3 control room personnel is approximately $5.26 \times 10^{-6}$ per year. The model assumes a delay of 2 hours before Waterford 3 is alerted by the St. Charles Parish industrial hot-line or through other agencies. It is most likely that the notification would occur sooner. The worst consequences of a release usually occur under low wind speeds; therefore there can be a considerable time lapse between the occurrence of an accident and the arrival of vapors at Waterford 3. The operators would be alerted and be able to take protective action during this period.

Given that the Union Pacific railroad line is much closer to Site 2 than it is to Waterford 3, further analysis is required to determine the potential hazard from this rail line.

\section{A-6.6.5 Aircraft Operations Evaluation}

Section 2.2.3.7 of Ref. NHA-1 evaluated aircraft hazards (nonsecurity related). Location of airports and their associated air traffic patterns in the vicinity of Waterford 3 are shown in Figures 2.2-4, 2.2-5a and 2.2-5b respectively of Ref. NHA-1. For the Triche Airstrip the annual probability of an airplane impacting a safety related nuclear structure is $1.5 \times 10^{-7}$. For New Orleans International Airport the value is $4 \times 10^{-7}$. Aircraft impacts for Site 2 require further evaluation to consider more recent aircraft patterns.

\section{A-6.6.6 Radiological Impacts from Waterford 3 Nuclear Plant}

An evaluation needs to be performed regarding the impact on the HTGR control room of radiological releases (normal and accident) from the Waterford 3 nuclear plant. Presuming that the Waterford 3 control room is much closer to any existing release point, it is expected that releases that might impact a Site 2 HTGR control room can be addressed through the design process.

\section{A-6.7 RISK MITIGATION}

Nearby hazardous activities were identified for the area within $5 \mathrm{mi}$ of the site. However, detailed analyses are required out to $10 \mathrm{mi}$ to ensure that the Waterford could be considered an acceptable site. It is expected that since the Waterford 3 nuclear plant has been sited at this location, siting an HTGR at an adjacent location would be considered acceptable. However, the close proximity to a rail line presents greater hazards for the HTGR plant and requires additional evaluation. Similarly, a more detailed evaluation of potential impacts to the HTGR as a result of radiological releases from Waterford 3 is necessary. More recent studies of river traffic also need to be performed. 


\section{A-6.8 REFERENCES}

NHA-1: "Waterford 3 Final Safety Analysis Report,” Revision 301 (09/07).

NHA-2: NUREG-0800,"Standard Review Plan for the Review of Safety Analysis Reports for Nuclear Power Plants: LWR Edition."

NHA-3: Regulatory Guide 4.7, "General Site Suitability Criteria for Nuclear Power Stations."

NHA-4: Electric Power Research Institute, "Full Scale Tornado Missile Impact Test," Report NP-148, Project 399, April 1976.

NHA-5: NRC Regulatory Guide 1.95, "Protection of Nuclear Power Plant Control Room Operators against an Accidental Chlorine Release," Revision 1, January 1977 (withdrawn).

NHA-6: NRC Regulatory Guide 1.78, "Evaluating the Habitability of a Nuclear Power Plant Control Room during A Postulated Hazardous Chemical Release," Revision 0, June 1974.

NHA-7 10 CFR 100, "Reactor Site Criteria" 


\section{A-7. Other Site Characteristics/Security Features}

\section{A-7.1 Description}

10 CFR 100.21(f) requires that site characteristics be such that adequate security plans and measures can be developed. The NRC has developed Regulatory Guide 4.7 (Ref. SSF-2) to address general site suitability criteria when selecting a new facility site. Within this document are distance criteria objectives that are intended to prevent damage to vital structures that should preclude plant damage and a possible radiological release.

However, plant security has become much more complex since the September 2001 terrorist attacks on the World Trade Center. Although Regulatory Guide 4.7 does provide sound judgment, additional considerations have been demonstrated to play an important part in selecting a site, thereby improving the security for a new facility.

\section{A-7.2 Importance}

Nuclear power plants have been identified by the Department of Homeland Security as a risk threat for a terrorist attack. The present commercial nuclear power plant fleet is required by federal law to protect the plants in order to prevent a radiological release to the public in excess of 10 CFR Part 100. In accordance with 10 CFR 73.1, "Purpose and Scope," paragraph (a)(1)(i) "A determined violent external assault, attack by stealth, or deceptive actions, including diversionary actions, by an adversary force capable of operating in each of the following modes: A single group attacking through one entry point, multiple groups attacking through multiple entry points, a combination of one or more groups and one or more individuals attacking through multiple entry points, or individuals attacking through separate entry points, with the following attributes, assistance and equipment: ...."

The current commercial nuclear fleet has a dedicated security officer force in place around the clock to respond to this occurrence. The NRC has defined a Design Basis Threat against which the nuclear facilities must be designed, and for which protection must ensure adequate mitigation in a threat event. Furthermore, the officer force is required to participate in and pass "force-on-force" drills to demonstrate protection adequacy.

\section{A-7.3 Risk}

The location of a site that cannot be protected adequately will not be granted a Physical Security Plan, which is required to operate the facility. Additional risks include more extensive security defense features to account for a site that is less desirable.

\section{A-7.4 Evaluation Criteria}

Initial selection of a site for improved security at this stage of the process is based on physical attributes. The site may be either greenfield, brownfield, or an existing nuclear power plant facility site. It should be noted that security can generally be modified through the design process (at a cost) to work with the selected site. Therefore, there are no physical features that would eliminate a proposed site. Thus a "Site Not Suitable" evaluation is not appropriate. There are multiple features, however, as discussed below, that must be considered for the new facility. 


\section{A-7.5 Evaluation}

\section{Acceptable Site}

$\bigotimes \quad$ Site Requires Further Evaluation (NOTE: This is a general issue evaluation - further evaluation of sub-areas is provided below)

\section{Site Not Suitable}

\section{A-7.6 Discussion}

\section{A-7.6.1 Site Type}

Site 2 is located within an area adjoining an existing operating nuclear power plant and is therefore considered an existing nuclear power plant site. Site 2 is situated in an industrialized area.

\section{A-7.6.2 Site Topography}

\section{A-7.6.2.1 Evaluation Criteria}

The site may be classified "Acceptable Site" for topography if the final grading of the facility will result with the site's Protected Area (PA) elevation either at the same elevation with respect to the surrounding Owner Controlled Area (OCA) or elevated above the surrounding OCA.

The site may be classified "Site Requires Further Evaluation" for topography if the final grading of the facility will result with the site's PA at a lower elevation with respect to the surrounding OCA.

\section{A-7.6.2.2 Evaluation}

$\bigotimes \quad$ Acceptable Site

\section{Site Requires Further Evaluation}

\section{Site Not Suitable}

\section{A-7.6.2.3 Discussion}

The basis of topography concerns is that an adversary gains an advantage by maintaining and controlling "higher ground." This gives the adversary the ability to potentially reach the plant at a faster than expected rate and provides a strategy advantage for use of arms against responding forces.

Figure 2.4-1 of Ref. SSF-1 is a topographical map of the site. The elevation of the site changes little in all directions and varies no more than approximately $10 \mathrm{ft}$. The site is located adjacent to the Mississippi River. The adjacent Waterford 3 nuclear plant site has been graded but the topography still remains generally flat. Based on the land being uniformly flat, this site is determined to be an acceptable site.

\section{A-7.6.2.4 Risk Mitigation}

Final grading would have to ensure that the PA grade remains equal to or above the surrounding facility areas grade. 


\section{A-7.6.3 Adjacent Facilities}

\section{A-7.6.3.1 Evaluation Criteria}

The site may be classified "Acceptable Site" for adjacent facilities if there are no other facilities or structures in the general vicinity of the PA boundary.

The site may be classified "Site Requires Further Evaluation" for adjacent facilities, if a facility or structure exists within a relatively close proximity to the PA boundary.

\section{A-7.6.3.2 Evaluation}

\section{Acceptable Site}

\section{Site Requires Further Evaluation}

\section{Site Not Suitable}

\section{A-7.6.3.3 Discussion}

Having a facility or structure within close proximity to the PA boundary allows the adversaries to use the structure for cover when firing upon responding forces. It also possibly provides adversaries the capability to gain close access to the PA boundary without observation, giving them a possible timeline advantage for an attack.

The site is in close proximity to facilities and structures located in the adjacent Waterford 3 nuclear plant complex. Although these facilities have tall building elevations and are nearby, the buildings are within a protected area and hence do not pose a security threat to Site 2.

The closest other industrial property to Waterford is owned by Agrico Chemicals Company, approximately $0.6 \mathrm{mi}$ east of Site 2 . Occidental Chemical Company also owns property and is located approximately $0.8 \mathrm{mi}$ to the east of the site. The height of the structures on these properties is unknown. This site requires further evaluation in order to determine the potential security threats posed by these nearby structures. The Waterford 3 nuclear plant has an approved physical security plan with these same structures located at approximately the same distance, so it is assumed that these facilities would not present an insurmountable security hazard for Site 2 .

\section{A-7.6.3.4 Risk Mitigation}

Once a final site is selected the surrounding structures, including cooling towers, if they're planned as a part of the HTGR plant design, should be reviewed to determine potential security threats and mitigation strategies. Using the assessed site as an example, one mitigation strategy may include combining the protected areas of Waterford 3 and Site 2 into one area with one set of alarm stations and one security force.

\section{A-7.6.4 Underground Pathways}

\section{A-7.6.4.1 Evaluation Criteria}

The site may be classified "Acceptable Site" for underground pathways if there are no underground pathways larger than 96 in $^{2}$ that either transverse the proposed site or if they transverse the site would have to surface areas within the proposed PA. 
The site may be classified "Site Requires Further Evaluation" for underground pathways if an existing underground pathway already exists and is expected to remain with surface openings that may be present within the PA.

\section{A-7.6.4.2 Evaluation}

\section{$\bigotimes \quad$ Acceptable Site}

\section{Site Requires Further Evaluation}

\section{Site Not Suitable}

\section{A-7.6.4.3 Discussion}

Underground pathways provide a possible entry point into the PA that is difficult to detect, assess, and protect against.

No underground infrastructure drawings were provided for the proposed site. It is assumed that any underground pathways would either remain completely buried or would be relocated as part of the new nuclear plant design. Based on this assumption Site 2 is determined to be acceptable.

\section{A-7.6.4.4 Risk Mitigation}

Design of the facility should consider minimizing outfalls (or the size of or access points to outfall discharges) and other plant underground pathways. Existing pathways should be reviewed to determine need, and whether they can be relocated or eliminated. Any opening to the surface within the proposed PA should be redesigned for elimination.

\section{A-7.6.5 Adjacent to Waterways}

\section{A-7.6.5.1 Evaluation Criteria}

The site may be classified "Acceptable Site" for locations adjacent to waterways if either the facility will not be situated directly on a waterway (water sources are remote and pumped to the facility) or if the design of the facility is such that no critical (safety related) structures will be physically located on the body of water.

The site may be classified "Site Requires Further Evaluation" for locations adjacent to waterways if the design of the facility is such that critical structures must be physically located on the body of water.

\section{A-7.6.5.2 Evaluation}

\section{\ Acceptable Site}

\section{Site Requires Further Evaluation}

\section{Site Not Suitable}

\section{A-7.6.5.3 Discussion}

Having a critical structure such as a safety related intake structure on a waterway provides an extreme challenge for the responding protective force to monitor and defend. In addition, there are multiple other potential challenges associated with controlling a waterway for boats and personnel. 
The boundary for the Waterford 3 site is approximately 1,500 ft from the nearby Mississippi River. It is not expected that the Site 2 design will require the siting of safety related structure on the waterway. Based on distance away from the river and the currently expected configuration of the nuclear plant cooling system, which is not safety related, Site 2 is determined to be acceptable.

\section{A-7.6.5.4 Risk Mitigation}

Final design of the water source should ensure that an ultimate heat sink requiring a critical structure located directly on the water is not required.

\section{A-7.6.6 Dangerous Facilities}

\section{A-7.6.6.1 Evaluation Criteria}

The site may be classified "Acceptable Site" for dangerous facilities if there are no other facilities or structures within the general vicinity of the owner controlled area (OCA).

The site may be classified "Site Requires Further Evaluation" for dangerous facilities, if a dangerous facility exists within a relatively close proximity to the OCA boundary.

\section{A-7.6.6.2 Evaluation}

\section{Acceptable Site}

$\bigotimes \quad$ Site Requires Further Evaluation

\section{Site Not Suitable}

\section{A-7.6.6.3 Discussion}

An example of a dangerous facility would be a chemical plant located within close proximity to a proposed site. Such a facility could be used for either a diversion or as a weapon to assist adversaries. Another example would be railroads lines that transverse close to the facility. The railroad may be transporting chemicals close to or adjacent to the facility.

Site 2 is located very near to an industrial complex with chemical processing facilities. As such, these facilities cause a general concern with proximity to a Site 2 . The closest railroad to the site is the Union Pacific Railroad, which runs across Entergy's property very close to the expected protected area Site 2 boundary (within $500 \mathrm{ft}$ ). In 1977, the rail line had an average of 18 trains pass by the site each day with approximately 100 cars per train (Section 2.2.2.1.2 of Ref. SSF-1). The railroad services all the chemical plants on the west (right descending) bank of the river. Some of the products it ships are dry fertilizers (phosphate based), caustic soda, chlorine, and numerous amounts of industrial chemicals. Based on the closeness of this railroad line to the site and the proximity of chemical facilities, Site 2 is considered to have some risk that will require further evaluation.

\section{A-7.6.6.4 Risk Mitigation}

An evaluation will be needed for the adjacent facilities to determine if risk mitigation measures are needed.

\section{A-7.6.7 High Traffic Area}

\section{A-7.6.7.1 Evaluation Criteria}


The site may be classified "Acceptable Site" for high traffic areas if there are no public roads immediately adjacent to the PA boundary.

The site may be classified "Site Requires Further Evaluation" for high traffic areas if there is a public road(s) immediately adjacent to the PA boundary.

\section{A-7.6.7.2 Evaluation}

\section{Acceptable Site}

$\bigotimes \quad$ Site Requires Further Evaluation

\section{Site Not Suitable}

\section{A-7.6.7.3 Discussion}

The Waterford 3 site is situated in an area where there are no public roadways situated adjacent or near to the PA boundary. The closest highway to Waterford 3 is Louisiana State Highway 18 (LA 18) approximately $1,500 \mathrm{ft}$ northeast. Approximately one-half mile to the southwest is Route 3127 . All other roadways near or adjacent to the designated site are internal Entergy company roadways with limited access. The closest railroad to the site is the Union Pacific Railroad, which runs across Entergy's property and approximately $500 \mathrm{ft}$ from the projected protected area boundary for Site 2. Because of the closeness of the railroad line, the site is going to require additional analysis in this area.

\section{A-7.6.7.4 Risk Mitigation}

An evaluation will be needed for the adjacent railroad line to determine if risk mitigation measures are needed.

\section{A-7.6.8 Detrimental Manmade Features}

\section{A-7.6.8.1 Evaluation Criteria}

The site may be classified "Acceptable Site" for detrimental manmade features if there are none in the area of the OCA.

The site may be classified "Site Requires Further Evaluation" for detrimental manmade features if they exist close to the OCA and the feature could be used in a negative manner.

\section{A-7.6.8.2 Evaluation}

\section{Acceptable Site}

\section{$\bigotimes \quad$ Site Requires Further Evaluation}

\section{Site Not Suitable}

\section{A-7.6.8.3 Discussion}

The comprehensive flood control and navigation plan for the Mississippi River consists of a levee system along the main stem of the river and its tributaries in the alluvial plain, reservoirs on the tributary streams, floodways to receive excess flow from the river, and channel improvements such as revetment, dikes, and dredging to increase channel capacity. Refer to the flooding evaluation of this report for an evaluation of these man-made features (Appendix A, Section A-4). 


\section{A-7.6.8.4 Risk Mitigation}

Refer to the flooding evaluation, Appendix A, Section A-4.

\section{A-7.6.9 Local Law Enforcement Agencies}

\section{A-7.6.9.1 Evaluation Criteria}

The site may be classified "Acceptable Site" for local law enforcement agencies (LLEA) if there are existing resources that can be of assistance during an adversarial event.

The site may be classified "Site Requires Further Evaluation" for LLEA if there are no existing or expected resources that could be of assistance during an adversary event.

\section{A-7.6.9.2 Evaluation}

\section{$\bigotimes \quad$ Acceptable Site}

\section{$\square \quad$ Site Requires Further Evaluation}

\section{Site Not Suitable}

\section{A-7.6.9.3 Discussion}

Site 2 is located adjacent to an existing nuclear power plant that has already established agreements with local emergency responders such as law enforcement agencies and fire departments to provide support to the plant. It is expected that similar agreements would be established for Site 2 with the LLEA as a part of the emergency plan established for the nuclear plant. Based on the location of the site and its proximity to the Waterford 3 nuclear plant, no special Site 2 considerations are necessary.

\section{A-7.6.9.4 Risk Mitigation}

None.

\section{A-7.6.10 Multiple Access Pathways to the Facility}

\section{A-7.6.10.1 Evaluation Criteria}

The site may be classified "Acceptable Site" for multiple access pathways if there are or can be planned multiple access points to the facility for vehicles.

The site may be classified "Site Requires Further Evaluation" for multiple access pathways if there will only be a single access point to the facility for vehicles.

\section{A-7.6.10.2 Evaluation}

\section{\ Acceptable Site}

\section{Site Requires Further Evaluation}

\section{Site Not Suitable}




\section{A-7.6.10.3 Discussion}

Having multiple access points to the facility allows the LLEA to respond in a more efficient manner from their present location when called upon.

Site 2 designers should consider having similar numbers of access points as the Waterford 3 nuclear plant, which has an NRC approved Physical Security Program.

\section{A-7.6.10.4 Risk Mitigation} site.

Final site design should ensure that at least two possible pathways exist for the LLEA to access the

\section{A-7.6.11 Site Size}

\section{A-7.6.11.1 Evaluation Criteria}

The site may be classified "Acceptable Site" for facility size if the planned facility is large and spatially open with large clear areas approaching the PA boundary.

The site may be classified "Site Requires Further Evaluation" for facility size if the planned facility is small, physically located on a compact area, or has congested areas adjacent to or approaching the PA boundary.

\section{A-7.6.11.2 Evaluation}

\section{Acceptable Site}

$\bigotimes \quad$ Site Requires Further Evaluation

\section{Site Not Suitable}

\section{A-7.6.11.3 Discussion}

Having open areas adjacent to the PA gives the security force an ability to view a potential threat and respond in a timely manner. The time required to respond to an adversarial threat is critical to the success of the actions. The greater the time period offered by site circumstance to be ready to respond affords responding forces the greatest chance of success.

RG 4.7 has a "general" siting criterion of 110 meters (360 ft) for standoff (SO) distance to a vital structure or vital equipment for blast considerations. However, these requirements are considered general guidelines. The RG goes on to state that any distance less than the proposed SO distance requires detailed analysis. Without the detailed plot plans for each area for the Site 2 facility, the exact distance available cannot be determined in this evaluation. The actual distances would be determined by blast analysis calculations based on the need to protect the plant against the design basis threat.

The proposed site is approximately $1,100 \times 1,500 \mathrm{ft}$. The closest industrial property is Agrico Chemicals Company approximately $0.6 \mathrm{mi}$ east of the site. It is anticipated that given the expected footprint of the site and location of the PA fence, there will be open areas adjacent to the PA and sufficient SO distance in the direction of these facilities that meets regulatory guidance. However, the railroad line discussed above resides within $500 \mathrm{ft}$ of the proposed Site 2 boundary. This could therefore present a problem with respect to meeting required SO distances. Because of these unknowns, the site requires further evaluation and a possible mitigation strategy to consider in the design. 


\section{A-7.6.11.4 Risk Mitigation}

The surrounding areas should be reviewed and modified if possible to clear any obstructions near or close to the PA boundary.

\section{A-7.7 RISK MITIGATION}

An evaluation will be needed to determine if risk mitigation measures are needed.

\section{A-7.8 REFERENCES}

SSF-1: "Waterford 3 Final Safety Analysis Report,” Revision 301 (09/07).

SSF-2: $\quad$ NRC Regulatory Guide 4.7, "General Site Suitability Criteria for Nuclear Power Stations." 


\section{A-8. Other Site Characteristics/Land Availability}

\section{A-8.1 Description}

This evaluation addresses the availability of the necessary land area and buffer zones for the plant, including switchyard and transmission facilities (switchyard and ties to offsite power), and the cost of acquiring those lands.

\section{A-8.2 Importance}

Federal regulations including 10 CFR 100.21, "Non-Seismic Siting Criteria" and 10 CFR 100.3, "Definitions" require every site to have an "Exclusion Area" defined by the regulations as that area surrounding the reactor, in which the reactor licensee has the authority to determine all activities, including exclusion or removal of personnel and property from the area (Ref. LAV-3).

The specific requirements relative to dose to the public at the EAB are given in $10 \mathrm{CFR}$ 50.34(a)(1)(ii)(D) as follows:

An individual located at any point on the boundary of the exclusion area for any 2 hour period following the onset of the postulated fission product release, would not receive a radiation dose in excess of 25 rem total effective dose equivalent (TEDE).

The NGNP project has a design objective to meet the Environmental Protection Agency's (EPA) protective action guidelines (PAGs) at the EAB for plume releases (1.0 rem for an early release). These PAGs are expressed in units of radiation dose (rem) and represent trigger or initiation levels that warrant preselected protective actions for the public if the projected (future) dose received by an individual in the absence of a protective action exceeds the PAG. Therefore, it should be demonstrated that offsite dose from radiological releases during accident conditions (required for plant siting and emergency planning purposes) are less than the EPA plume PAGs. By meeting this design objective it is clear that the prompt safety goal will be met by orders of magnitude (Refs. LAV-5 and LAV-6).

The EPA Manual of Protective Action Guides and Protective Actions for Nuclear Incidents (Ref. LAV-5) recommends PAGs and corresponding protective actions for both the early and intermediate phases of an atmospheric release of radioactivity. The PAGs are recommended criteria against which projected doses to members of the public are compared in determining whether corresponding protective actions should be taken.

The PAGs for the early phase of an incident (e.g., hours to days) given in Table 2-1 of the EPA Manual are:

- Evacuation: $1-5 \mathrm{rem}^{\mathrm{c}}$

- Administration of stable iodine: $25 \mathrm{rem}^{\mathrm{d}}$

A site should include enough contiguous land to meet the exclusion area requirements summarized above. The cost to obtain the property and/or land rights may have a large effect on overall plant costs.

c. This PAG is the sum of the "effective dose equivalent" resulting from exposure to external sources and the "committed effective dose equivalent" incurred from all significant inhalation pathways.

d. This is the committed dose equivalent to the thyroid from radioiodine. 


\section{A-8.3 Risk}

The required exclusion area size is based on radiological criteria in 10 CFR 50.34. The size of the exclusion area must ensure that the criteria in 10 CFR 50.34 are met, and the licensee must demonstrate that it can exercise control over the area as required by 10 CFR 100.21 and 10 CFR 100.3. In addition, as stated above, it is the objective of the NGNP project to meet the more conservative EPA PAGs at the EAB. Failure to meet exclusion area size and control requirements could cause the site to be deemed unacceptable (Refs. LAV-2, LAV-3, and LAV-4).

\section{A-8.4 Evaluation Criteria}

The site may be classified "Acceptable Site" if it is determined to have sufficient land in an appropriate configuration available at an acceptable cost to allow the plant facilities to be sited in such a way as to satisfy the requirements of 10 CFR 100 and 10 CFR 50.34 with respect to exclusion area control and $\mathrm{EAB}$ dose.

The site may be classified "Site Requires Further Evaluation" if it is estimated that the EAB distance will not meet the requirements of the EPA PAGs and 10 CFR 50.34, or if it has been determined that it would not be possible to demonstrate control over all of the activities within the EAB as required by 10 CFR 100 (Refs. LAV-3 and LAV-4). A site would also require further evaluation if issues with the owner boundary, site configuration, or transmission corridors arise. Similarly, a potential challenge to the site could occur if the cost of relocating existing site structures or facilities is determined to be excessive or the purchase of additional land is required,.

The site may be classified "Site Not Suitable" if it is estimated that the nearest EAB distance will not meet the requirements of 10 CFR 100, and dose limits the EPA PAGs and those of 10 CFR 50.34 are not met, or if it is determined that it would not be possible to demonstrate control over all of the activities within the EAB.

\section{A-8.5 Evaluation}

\section{Acceptable Site}

Site Requires Further Evaluation

Site Not Suitable

\section{A-8.6 Discussion}

\section{A-8.6.1 Site Type}

Site 2 is located adjacent to an operating nuclear plant site.

\section{A-8.6.2 Land Availability Analysis}

The land availability analysis focuses on four areas: land availability, exclusion area size and control, land ownership, and cost acceptability.

\section{A-8.6.2.1 Land Area Available}

The gross footprint for the proposed HTGR nuclear plant, including all facilities and support buildings, is about 40 acres (approximately $1,100 \times 1,500 \mathrm{ft})(\mathrm{Ref}$. LAV -1$)$. The site property upon which he existing nuclear plant is located covers over 3,000 acres. There are several locations for Site 2 with 
sufficient available area to site this size or an even larger HTGR facility. Each of the potential locations has suitable access for supply of steam and transmission of electricity to the local industrial facilities and to the existing nuclear plant substations for access to the regional electrical grid.

\section{A-8.6.2.2 Exclusion Area Control}

The EAB for the proposed reactor type is assumed to be the circumference of a circle approximately 400 meters $(1,300 \mathrm{ft}$ ) in radius, centered on the reactor center point (Ref. LAV-6), as depicted in Figure 1 of this report.

Each of the potential locations for the HTGR facility was selected to ensure that the EAB of the facility does not encompass the existing nuclear plant reactor or any publicly accessible road, waterway, railway, or residence. One area requiring further review is the impact of the adjacent railroad line on the $\mathrm{EAB}$ radius.

\section{A-8.6.2.3 Land Ownership}

All of the land considered for locating the HTGR facility is owned by the existing nuclear plant owner. No additional land purchases are anticipated. Therefore, no land ownership issues are anticipated.

\section{A-8.6.2.4 Cost Acceptability}

As previously discussed, the current nuclear plant owner owns the property upon which the facility, exclusion area, and transmission corridor would be located. No additional land purchases are anticipated to be required. Therefore, cost acceptability issues are not anticipated.

\section{A-8.7 Risk Mitigation}

No risk mitigation is judged to be required since there is sufficient land area available on the existing nuclear plant site for locating the HTGR facility.

\section{A-8.8 References}

LAV-1. INL/EXT-11-23282, "NGNP Project Evaluation of Siting a HTGR Co-generation Plant on an Operating Commercial Nuclear Power Plant," Revision 0, October 2011.

LAV-2. "Waterford 3 Final Safety Analysis Report,” Revision 301 (09/07), Chapter 2.

LAV-3. $\quad 10$ CFR 100.21, "Non-Seismic Siting Criteria."

LAV-4. $\quad 10$ CFR 100.3, "Definitions.”

LAV-5. $\quad$ EPA 400-R-92-001, "Manual of Protective Action Guides and Protective Actions for Nuclear Incidents," U.S. Environmental Protection Agency, Revised, 1991.

LAV-6. INL/MIS-10-19799, "Determining the Appropriate Emergency Planning Zone Size and Emergency Planning Attributes for an HTGR,” Revision 0, October 2010. 


\section{A-9. Other Site Characteristics/Site Constructability Factors}

\section{A-9.1 Description}

The feasibility of physically constructing a nuclear plant at a particular site is dependent on two main issues (1) the ability to deliver construction equipment/materials and major plant components to the reactor location, and (2) the ability to deliver plant output in the form of electricity to the transmission grid, process heat, and/or steam. There are numerous other factors that can pose major impacts and/or risks to construction costs, including the availability of an adequate and skilled work force, difficulty establishing a footprint for the reactor building, preexisting subsurface contamination, depth of required evacuation, subsurface soil type, and availability of construction materials.

\section{A-9.2 Importance}

Overall construction costs can vary greatly from site to site, depending on the types and characteristics of the subsurface soil and existing infrastructure surrounding the site. An unfavorable subsurface soil condition, (e.g., contamination, unstable) may require cost-prohibitive remediation or soil conditioning during excavation. Soil conditions and/or state and local regulations may restrict excavation and depth of excavation under certain conditions.

The plant must connect to the local industrial plant end users and the regional electrical grid. There may be large obstacles to providing those connections. Factors include the differences in the distance to the end users and the nearest load center, whether it is feasible to procure the land for the necessary rights of way, and whether it is likely that approval from Federal Energy Regulatory Commission for a transmission line as proposed will be granted.

Large reactor components must be delivered either by rail or by barge. If accessible to the plant, barges are a good method of transporting the heavy loads involved. If not, a connection to a railroad line must be provided. Similar to the transmission line, if the distance is too great, the land cannot be procured, or federal, state or local approvals are unlikely, it could be cost prohibitive to install a spur to the site.

For installations where process heat and/or steam are a desired output, the feasibility of accomplishing this in a cost effective manner must be analyzed. There may be logistical limitations to providing process heat and/or steam, especially if the recipient facility covers large areas of land.

\section{A-9.3 Risk}

The major risk factors include the ability to permit and prepare the site, including excavations at acceptable cost; permit and install transmission lines, if there are no existing lines; the ability to transport heavy loads to the site; and the ability to deliver process heat and/or steam at the desired conditions to the desired location. Lack of availability of construction materials, subsurface contamination and site access could also impact the project. These risks may cause the site to be cost-prohibitive.

\section{A-9.4 Evaluation Criteria}

A site may be classified as "Acceptable Site" if it is determined that the site can be prepared at acceptable cost, there is sufficient access to the transmission line grid, there are means to get major plant equipment to the site location, and it is feasible to get process heat and/or steam from and to the required location at the required conditions, all in a cost-effective manner. 
A site may be classified as a "Site Requires Further Evaluation" if the site requires further examination of specific issues. Such issues might include permitting issues, ownership boundary issues, compensation issues, transmission right-of-way issues, contamination disposition, etc. For sites requiring process heat and/or steam, the designer must look into the distance and traverse a path for getting the product to the desired location at the required design conditions, and back. Another issue would be the cost of installing a rail spur or new transmission lines, which has yet to be determined.

A site may be classified as "Site Not Suitable" if it is determined that the subsurface soil conditions make site preparation and/or related permitting questionable or if such preparation is cost prohibitive. This includes deliver of either construction equipment or major plant components (e.g., reactor vessel) or it is judged cost-prohibitive to do so; if it is determined not feasible to provide transmission access or it is judged cost-prohibitive to do so; if process heat and/or steam cannot be provided at the required design conditions or it is judged cost-prohibitive to do so; or site remediation is cost-prohibitive.

\section{A-9.5 Evaluation}

\section{Acceptable Site}

$\bigotimes \quad$ Site Requires Further Evaluation

Site Not Suitable

\section{A-9.6 Discussion}

\section{A-9.6.1 Site Type}

Site 2 is located adjacent to an operating nuclear plant site on the banks of the Mississippi river.

\section{A-9.6.2 Site Constructability Factors Analysis}

Site 2 is located near the operating Waterford 3 nuclear plant. This plant has substantial existing infrastructure in place such as transmission lines, major roadways, railways, and barge access. There is also local and state government acceptance of nuclear power. It is assumed that a qualified workforce is available in the area sufficient to support HTGR plant construction. The site is also closely located to major industrial plants (all less than $2 \mathrm{mi}$ from the site) that are potential off-takers of energy from the HTGR facility. Scoping evaluations of Site 2 and a review of Ref. SCF-1 were performed and several conclusions regarding the site were identified.

There are several locations on the Site 2 property that have adequate area and subsurface soil conditions for construction of the HTGR facility.

Large components can be shipped to the site by barge on the Mississippi River and can be transported from the river to the construction area. The original Waterford 3 construction and major component replacement deliveries and handling were completed successfully using similar methods and equipment.

There are restrictions on excavations within 1,500 ft of the banks of the Mississippi River. All potential sites are located beyond this restricted zone.

Recent experiences with excavations that include subsurface dewatering indicate that there are acceptable means for handling of waste soil and water. Settling ponds are commonly used to achieve acceptable silt levels in water returned to the river.

Additional evaluation and development of the final excavation plan is required to confirm that the excavations will not adversely affect the existing nuclear plant operation. 
There is sufficient railroad and highway access to the site for general equipment and material delivery. An onsite concrete plant can be erected and operated to support plant construction. This was the method used to supply the concrete for the existing nuclear plant.

It is expected (although not confirmed in this evaluation) that the existing site electrical substation will provide access to the regional grid.

All of the property over which routing of steam and electricity to the industrial plants is controlled by the owner of the nuclear plant or the owners of the industrial facilities. Obtaining rights of way for this purpose is judged to be favorable.

If sale of excess power to the regional grid is anticipated (as opposed to consumption of electricity by industrial off-takers), it is assumed that existing offsite transmission lines have adequate capacity, but further analysis is needed to confirm this assumption. Appendix Sections A-3 and A-8 of this report discuss this topic further.

Delivery of major plant components and construction equipment was generally evaluated for Site 2 . Site 2 is located adjacent to an existing commercial nuclear power facility which is in close proximity (within $2 \mathrm{mi}$ ) of other large industrial facilities. There is both barge and rail access to the site (Ref. SCF-1). Transportation and delivery of heavy loads and construction supplies/equipment to Site 2 is considered feasible.

In regards to labor force, the construction of a nuclear power plant is very labor-intensive. Since the site is located within 1 hour of a major metropolitan area, and considering that a nuclear power plant was previously constructed in the area, it is assumed that a construction labor force would be available.

The amount of excavation and the associated cost is likely to vary considerably from area to area in the Waterford area. One consideration is the topography of the site and the amount of excavation required in order to establish a footprint for the plant. Another consideration is the required depth of the reactor building versus the level at which bedrock exists. Site 2 is relatively flat and bedrock is very deep (see Section 2.5.4 of Ref. SCF-1) so excavation or removal of rock is not a concern. However, because of the site's deep soil conditions and an anticipated depth of excavation of at least $160 \mathrm{ft}$ (Ref. SCF-2), the project will incur substantial costs associated with dewatering and excavation retaining walls and foundation designs intended to mitigate excess settlement. Hauling earthen fill to support the structure foundation may be required and presents others risks and costs to the project.

Nuclear plant construction typically requires large quantities of concrete. Since quarries are not located near the site and because large quantities of concrete will be needed, it will likely be desirable to construct a concrete plant onsite as was done during the construction of the existing nuclear plant. This approach is often used with large projects where significant quantities of concrete are needed. Doing so offers an effective means for delivery of concrete for the project. Aggregate, cement and other materials necessary to make concrete could be delivered by rail line, barge, or highway; therefore, concrete availability is considered acceptable.

\section{A-9.7 Risk Mitigation}

Because this site already includes an operating nuclear plant and the constructability issues for the HTGR facility are similar to those for construction of the existing nuclear plant, the constructability risks are judged to be low. A preliminary analysis of the potential impacts on the operating nuclear plant during construction of the HTGR should be completed early in the HTGR facility development project to support preparation of a construction plan that results in acceptable impact on the existing nuclear plant operation. 


\section{A-9.8 References}

SCF-1. "Waterford 3 Final Safety Analysis Report," Revision 301 (09/07), Chapter 2.

SCF-2. INL/EXT-11-23282, "NGNP Project Evaluation of Siting a HTGR Co-generation Plant on an Operating Commercial Nuclear Power Plant," Revision 0, October 2011. 
Appendix B

HTGR Impacts on Waterford 3 


\section{Appendix B HTGR Impacts on Waterford 3}

\section{B-1. Introduction}

The purpose of this appendix is to provide a summary description of potential hazards and key impacts that HTGR facility design, licensing, construction, and operation may have on the existing Waterford 3 nuclear facility. This is not intended to be an exhaustive or comprehensive listing, but is a summary of key areas and interfaces to be considered when evaluating an HTGR deployment project in an area near an operating nuclear power plant. It includes selected references to portions of the Waterford 3 Final Safety Analysis Report (FSAR).

\section{B-2. Effects of HTGR Effluents and Releases on Waterford 3}

\section{B-2.1 Waterford 3 Control Room Habitability}

Radiological releases from postulated licensing basis events from the HTGR module are expected to be bounded by postulated Waterford 3 releases because of the reduced HTGR reduced radionuclide inventory and release characteristics, when compared to the postulated light water reactor (LWR) events already evaluated in the FSAR. However, the specific impacts of a release from the HTGR plant on key Waterford 3 protective features and setpoints would need to be evaluated to determine if the existing features adequately address those external HTGR affects. Areas to be considered include:

- The capability of the Waterford 3 control room habitability system to adequately protect control room operators in the event of a radiological and/or helium release from the HTGR facility. This evaluation would include a review of the set-point for isolation of the Control Room Emergency Filtration System (Waterford 3 Technical Specification (TS) 3/4.7.6). This evaluation would also include a review of the adequacy of the existing operability modes for habitability systems, which may need to be updated to reflect the impacts of HTGR operation. For instance, when in plant Modes 5 or 6 , adequate protection of the Waterford 3 operators can currently be addressed by the suspension of core alterations when protective equipment or systems are inoperable. This protection may not be adequate once the HTGR facility is operating, since a radiological release from the HTGR facility could occur during the period of Waterford 3 protective system inoperability.

- Related to the above discussion, the existing setpoints and mode applicability requirements are contained in the Waterford 3 TS. For example: Table 3.3-6, "Radiation Monitoring - Control Room Intake Monitor," would need to be evaluated for adequacy.

- The existing Waterford 3 radiological effluent release points are within the restricted area boundary (with the exception of the discharge canal), as reflected in Waterford 3 FSAR Figure 2.1-4. The release points were determined and established based on the sources of the releases being primarily internal to the Waterford 3 facility (steam generators, etc.). Once the specific release types and characteristics are established for the HTGR facility, the potential for impacts on the Waterford 3 release locations and monitoring set-points would need to be re-assessed. For example, would the turbine building ventilation exhaust stream be impacted if an HTGR release or discharge occurs and is partially entrained in the Turbine Building ventilation intake? At the conclusion of this assessment and the integration of any HTGR impacts, the descriptions of monitoring, sample points, and limits contained in FSAR Section 11.5 and associated documents may need to be updated.

- Certain postulated licensing basis events occurring at the HTGR facility result in the release of large volumes of helium that contains radionulclides. The impacts of such releases on general site 
habitability at Waterford 3 would need to be evaluated. For instance, could a portion of the released helium volume be transported and entrained in various heating, ventilating, and air conditioning intakes at the Waterford 3 facility? The result of this evaluation would likely form an additional discussion within existing FSAR Section 2.2.3, "Evaluation of Accidents at Offsite Facilities."

\section{B-2.2 Waterford 3 Offsite Dose Analyses}

The Waterford 3 offsite dose analyses would need to be reassessed to determine any impacts from the HTGR facility and its structures. As an example, the wake factors assumed in the analyses of radionuclide transport and offsite dose could be affected by the HTGR structures, depending on their relative location, dimensions, and local meteorological conditions.

\section{B-2.3 Water Use and Existing Discharge Permits}

The Waterford 3 facility currently operates within the requirements and restrictions established in a series of federal, state, and local licenses and permits. These existing agreements may be impacted by the addition of the HTGR facility and its effluents, and would need to be evaluated for any necessary changes.

\section{B-3. Miscellaneous Issues}

\section{B-3.1 Ground motion and seismic analyses}

The analyses of ground motion and the associated Waterford 3 seismic analyses are described and presented in FSAR Sections 3.7 and 3.8. HTGR impacts could be created during both the initial excavation/construction phase and from the erected facility's operation phase. The analyses would need to be evaluated to determine if the HTGR facility impacts the inputs, analysis methods, or results. As an example, soil-structure interaction is described in FSAR Section 3.7.2.4, with the following key conclusion, that could be impacted by the HTGR's "adjacent structures":

All seismic Category I structures are located on a single common mat foundation. By virtue of this arrangement, the effects of adjacent structures on the soil-structure interaction response are automatically eliminated, leading to a simplified analysis.

\section{B-3.2 Emergency Planning and Security Programs}

The addition of the HTGR facility to the Waterford location will require the reevaluation and integration of a number of existing area boundaries and associated programs, such as:

- Exclusion Area Boundary definition and integration (FSAR Section 2.1 and Figure 2.1-3)

- Emergency plan reevaluation and integration, including the arrangement of the emergency planning zone(s), the location and responsibilities assigned to emergency facilities (emergency operations facility, technical support center, operations support center, and offsite agency response coordination,

- Coordination and potential integration of the site security force(s) responsible for the Waterford 3 and HTGR facilities.

\section{B-3.3 Spent Fuel Handling and Storage}

The plan for spent fuel handling and storage at Waterford 3 (including any plans for future dry cask storage) could be impacted by the inclusion of the spent fuel volumes and storage plan for the HTGR facility (FSAR Section 9.1), and would need to be evaluated. 


\section{B-3.4 Impact on Ultimate Heat Sink Capabilities}

The HTGR modules utilize the atmosphere as their ultimate heat sink (UHS) and reject heat to the UHS using active systems during normal plant operation and via passive heat rejection (reactor cavity cooling system) during accident conditions. Since the HTGR modules will likely be located in proximity to Waterford 3, and both facilities are rejecting heat to the atmosphere, the affects of the HTGR facility on the Waterford 3 UHS (FSAR Figure 9.2-5) will need to be evaluated, including the potential effects of thermal plumes or atmospheric stagnation on the assumed performance of the UHS (FSAR Section 9.2.5).

\section{B-3.5 Missile protection}

Section 3.5 of the Waterford 3 FSAR describes how the facility has addressed missile protection in order to conform to 10 CFR 50, Appendix A General Design Criterion 4, "Protection Against Postulated Missiles." The missiles that have been considered are those that could result from plant related operating, shutdown, and accident conditions, including failures within and outside the containment, environmentally generated missiles, and site proximity missiles. Once the design and location of the HTGR facility are established, the potential for additional "site proximity missiles" coming from the HTGRs will need to be evaluated and considered in the HTGR site orientation.

\section{B-3.6 Decommissioning Plan and Funding}

The Waterford 3 site currently maintains a plan, schedule, and funding source to provide for the decommissioning of the existing site (see 10 CFR 50.75 requirements). This overall plan, and related

funding, will need to be reevaluated to address the impacts and potential integration of the HTGR facility into the overall decommissioning plan.

\section{B-3.7 Offsite Power and Grid Reliability}

The availability and reliability offsite power supplying Waterford 3 may be impacted by the new offsite power connections associated with the HTGR facility (FSAR Chapters 8 and 15). This potential impact would need to be evaluated once that proposed configuration is established.

\section{B-3.8 Shared Systems}

It is not anticipated that the HTGR will share any systems with Waterford 3 that are relied upon to perform a safety function at either facility. However, in the event that system sharing is considered for certain plant functions (i.e. switchyard, fire protection), the applicability of General Design Criterion 5, "Sharing of Structures, Systems and Components" would need to be addressed and resolved. (See FSAR Section 3.1.5)

\section{B-3.9 Integrated "Plant" Risk from the Combined Facilities and Waterford 3 Probabilistic Risk Assessment Impact}

The historical risk metrics, core damage frequency, and large early release frequency that apply to LWRs, do not apply to HTGRs and are not used as regulatory compliance criteria. Instead, an event frequency-consequence curve is defined based on established regulatory criteria for protection of the health and safety of the public and the environment. For a multi-module HTGR plant facility, the integrated risk from licensing basis events for the combination of HTGR modules at the plant site is calculated on a "per plant-year" basis within this frequency-consequence framework. 
If required, a method for assessing and evaluating the integrated risk of the combined Waterford 3 and HTGR plant will need to be developed to provide for both technical evaluations of overall affects on plant health and safety, and for compliance reviews by the NRC for the combined complex. This method will need to account for the different sets of risk metrics that are applied to each of the two plant types (LWR and HTGR), and arrive at some integrated risk evaluation structure. In addition, the construction and operation of the HTGR facility may require that the existing Probabilistic Risk Assessment for Waterford 3 be updated to address any new or different inputs and impacts from the HTGR facility.

\section{B-3.10 Potential Waterford 3 Impacts during HTGR Construction}

The table below provides a summary listing of hazards or impacts to Waterford 3 that may be created by HTGR facility construction. This listing is typical of the hazards listing developed for multiunit nuclear plant sites where unit construction is planned while other units are operating. A specific evaluation of such hazards, along with a description of how they will be managed and controlled, is required by 10 CFR 52.79(a)(31).

\begin{tabular}{|ll|}
\hline \multicolumn{1}{|c|}{ HTGR Construction Activity } & \multicolumn{1}{c|}{ Potential Waterford 3 Hazard or Impact } \\
\hline & Impact on overhead power lines \\
& Impact on transmission towers \\
& Impact on underground conduits, piping, tunnels, etc. \\
& Impact on site access and egress \\
Site Exploration, Grading, Clearing, & Impact on drainage facilities and structures (also refer to the \\
Installation of Drainage and Erosion & "constructability" discussion in appendix a) \\
Control Measures, etc. & Impact on onsite transportation routes \\
& Impact on slope stability \\
& Impact of increased soil erosion and local flooding \\
& Impact of construction-generated dust and equipment exhausts \\
& impact of encroachment on plant protected or vital areas \\
& Impact of encroachment on structures and facilities \\
\hline Boring, Drilling, Pile Driving, Dredging, & Impact on the levee adjacent to the plant site \\
Demolition, & Impact on underground conduits, piping, tunnels, etc. \\
Excavation, Dewatering, etc. & Impact on structural integrity \\
& Impact on slope stability \\
& Impact of ground vibration \\
\hline Equipment Movement, Material & Impact of overpressure from use of explosives \\
Delivery, Vehicle Traffic. etc. & Impact on overhead power lines \\
& Impact on transmission towers \\
& Impact on underground conduits, piping, tunnels, etc. \\
& Impact of crane load drops \\
& Impact of crane or crane boom failures \\
& Impact of vehicle accidents \\
& Impact of vehicle runaways \\
& Impact on local traffic congestion/patterns \\
\hline & \\
&
\end{tabular}




\begin{tabular}{|c|c|}
\hline HTGR Construction Activity & Potential Waterford 3 Hazard or Impact \\
\hline \multirow{3}{*}{$\begin{array}{l}\text { Equipment And Material Laydown, } \\
\text { Storage, Warehousing, etc. }\end{array}$} & $\begin{array}{l}\text { Impact of releases of stored flammable, hazardous or toxic } \\
\text { materials }\end{array}$ \\
\hline & Impact of increased local flooding \\
\hline & $\begin{array}{l}\text { Impact of wind-generated, construction-related debris and } \\
\text { missiles }\end{array}$ \\
\hline \multirow{6}{*}{$\begin{array}{l}\text { General Construction, Erection, } \\
\text { Fabrication, etc. }\end{array}$} & $\begin{array}{l}\text { Impact on instrumentation and control systems and } \\
\text { components }\end{array}$ \\
\hline & Impact on electrical systems and components \\
\hline & Impact on cooling water systems and components \\
\hline & Impact on radioactive waste release points and parameters \\
\hline & $\begin{array}{l}\text { Impact of abandonment of structures, systems, and } \\
\text { components (SSCs) }\end{array}$ \\
\hline & Impact of relocation of SSCs \\
\hline \multirow{3}{*}{$\begin{array}{l}\text { Connection, Integration, Tie-In, Testing, } \\
\text { etc. }\end{array}$} & $\begin{array}{l}\text { Impact on instrumentation and control systems and } \\
\text { components }\end{array}$ \\
\hline & Impact on electrical and power systems and components \\
\hline & Impact on cooling water systems and components \\
\hline \multirow{2}{*}{ General Site Construction Activities } & Impact on site security systems \\
\hline & Impact on emergency planning \\
\hline
\end{tabular}

